\title{
Stratigraphic and Structural Characterization of the OU-1 area at the former George Air Force Base, Adelanto, Southern California
}

\author{
R. D. Catchings, G. Gandhok, and M.R. Goldman
}

January 25, 2001

U. S. Geological Survey Open-File Report 01-60

\footnotetext{
This report is preliminary and has not been reviewed for conformity with U. S. Geological Survey editorial standards or with the North American Stratigraphic Code. Any use of product names is for descriptive purposes only and does not imply endorsement by the U. S. Government.
} 


\section{Table of Contents}

Introduction

Local Geology and Tectonics

Tectonism and Regional Faulting 9

Seismic Survey 9

Data Acquisition $\quad 9$

GAFB $1 \quad 10$

GAFB $2 \quad 10$

GAFB $3 \quad 10$

Seismic Imaging Methods 10

Seismic Refraction $\quad 20$

Seismic Reflection $\quad 20$

Data Analysis $\quad 21$

Seismic Refraction Velocity Analysis $\quad 21$

Seismic Reflection Processing $\quad 21$

$\begin{array}{ll}\text { Seismic Images } & 22\end{array}$

Seismic Refraction Images $\quad 22$

Seismic Reflection Images $\quad 27$

Profile GAFB 1

Unmigrated Data (GAFB 1) 27

Migrated Data (GAFB 1) 27

Profile GAFB 2

Unmigrated Data (GAFB 2) 31

Migrated Data (GAFB 2) 31

Profile GAFB $3 \quad 36$

Unmigrated Data (GAFB 3) 36

Migrated Data (GAFB 3) 36

Three-Dimensional Image $\quad 40$

$\begin{array}{lr}\text { Discussion } & 40\end{array}$

$\begin{array}{ll}\text { Conclusions and Suggestions } & 42\end{array}$

Acknowledgements 43

References $\quad 47$

Appendix 1 Survey Data For Profile GAFB 1 48

Appendix 2 Survey Data For Profile GAFB 1

Appendix $3 \quad$ Survey Data For Profile GAFB 1 59

Appendix 4 Well Logs 65 


\section{List of Tables}

Table 1. Acquisition Parameters

\section{List of Figures}

Fig.1 Location map and geologic provinces near the study area 5

Fig. 2 Location map of seismic profiles and outline of GAFB 6

Fig. 3 Basic stratigraphic units in the study area 8

Fig.4 Relative geophone elevations vs. distance along GAFB 1 11

Fig.5. Geophone variation from a straight line along GAFB 1 11

Fig.6. Relative shot point elevation vs. distance along GAFB1 12

Fig.7. Shot point variation from a straight line along GAFB 1

Fig.8. Fold as function of CDP along GAFB $1 \quad 13$

Fig.9. Relative geophone elevations vs. distance along GAFB 2

Fig.10 Geophone variation from a straight line along GAFB 2 14

Fig.11 Relative shot point elevation vs. distance along GAFB2 15

Fig.12 Shot point variation from a straight line along GAFB 2

Fig.13 Fold as function of CDP along GAFB 2 16

Fig.14 Relative geophone elevations vs. distance along GAFB $3 \quad 17$

Fig.15 Geophone variation from a straight line along GAFB 3 17

Fig.16 Relative shot point elevation vs. distance along GAFB $3 \quad 18$

Fig.17 Shot point variation from a straight line along GAFB $3 \quad 18$

Fig.18 Fold as function of CDP along GAFB $3 \quad 19$

Fig.19a-c Velocity inversion models along each profile 23

Fig.19d Semi 3-D velocity model for the seismic profiles 24

Fig.19e Semi 3-D velocity model for the seismic profiles 25

Fig.19f Semi 3-D velocity model for the seismic profiles 26

Fig.20 Unmigrated seismic reflection image along GAFB1 28

Fig.21a Migrated seismic reflection image along GAFB 1

Fig.21bc Migrated seismic reflection image along GAFB $1 \quad 30$

Fig.22 Unmigrated seismic reflection image along GAFB 2

Fig.23a Migrated seismic reflection image along GAFB 2

Fig.23bc Migrated seismic reflection image along GAFB2 34

Fig.23de Alternative interpretation of profile GAFB 2

Fig.24 Unmigrated seismic reflection image along GAFB $3 \quad 37$

Fig.25a Migrated seismic reflection image along GAFB $3 \quad 38$

Fig.25bc Migrated seismic reflection image along GAFB $3 \quad 39$

Fig.26 Semi-3-D seismic reflection image across the study area 41

Fig.27 TCE concentration map at GAFB 44

Fig.28 Major mapped faults in the Victorville area 45

Fig.29 Lineaments immediately southeast of GAFB 46 


\section{Introduction}

The former George Air Force Base (GAFB), now known as the Southern California Logistics Airport (SCLA), is located in the town of Adelanto, approximately $100 \mathrm{~km}$ northeast of Los Angeles, California (Fig. 1). In this report, we present acquisition parameters, data, and interpretations of seismic images that were acquired in the OU-1 area of GAFB during July 1999 (Fig. 2).

GAFB is scheduled for conversion to civilian use, however, during its years as an Air Force base, trichlorethylene (TCE) was apparently introduced into the subsurface as a result of spills during normal aircraft maintenance operations. To comply with congressional directives, TCE contaminant removal has been ongoing since the early-tomid 1990s. However, only a small percentage of the TCE believed to have been introduced into the subsurface has been recovered, due largely to difficulty in locating the TCE within the subsurface.

Because TCE migrates within the subsurface by ground water movement, attempts to locate the TCE contaminants in the subsurface have employed an array of ground-water monitoring and extraction wells. These wells primarily sample within a shallow-depth $(\sim 40 \mathrm{~m})$ aquifer system. Cores obtained from the monitoring and extraction wells indicate that the aquifer, which is composed of sand and gravel channels, is bounded by aquitards composed largely of clay and other fine-grained sediments. Based on well $\operatorname{logs}$, the aquifer is about 3 to $5 \mathrm{~m}$ thick along the seismic profiles. A more thorough understanding of the lateral variations in the depth and thickness of the aquifer system may be a key to finding and removing the remaining TCE. However, due to its complex depositional and tectonic history, the structural and stratigraphic sequences are not easily characterized. An indication of the complex nature of the structure and stratigraphy is the appreciable variation in stratigraphic sequences observed in some monitoring wells that are only a few tens of meters apart.

To better characterize the shallow (upper $100 \mathrm{~m}$ ) stratigraphy beneath GAFB, the US Environmental Protection Agency (USEPA) contracted the US Geological Survey (USGS) to acquire three seismic reflection/refraction profiles within an area known as Operational Unit \#1 (OU-1). The principal objective of the seismic survey was to laterally characterize the subsurface with respect to structure and stratigraphy. In particular, we desired to (1) laterally "map" stratigraphic units (particularly aquifer layers) that were previously identified in monitoring wells within the OU-1 area and (2) identify structures, such as faults and folds, that affect the movement of ground water. Knowledge of lateral variations in stratigraphic units and structures that may affect those units is useful in constructing ground-water flow models, which aid in identifying possible TCE migration paths within the subsurface. Stratigraphic and structural characterization may also be useful in identifying surface locations and target depths for future wells (Catchings et al., 1996). Proper siting of wells is important because a welldefined aquifer is apparently not present in all locations at GAFB, as indicated by lithologic logs from existing wells (Montgomery Watson, 1995). Proper depth placement of monitoring and extraction wells is important because wells that are too shallow will not sample within the aquifer, and wells that are too deep risk puncturing the aquitard and allowing contaminants to flow to deeper levels.

\section{Local Geology and Tectonics}


Cox and Hillhouse (2000) summarized the geology of GAFB and the nearby Victorville region by including the findings of a number of other researchers, including IT Corp (1992), Sibbet (1996; 1999), Montgomery Watson (1995), Chrisley (1997), Cox et al (1998), and Cox and Tinsley (1999). Below we summarize the geologic study of Cox and Hillhouse (2000) as it relates to the GAFB area.

The present-day structural and stratigraphic framework of the GAFB area is related to the evolution of the San Andreas Fault (SAF), which trends NW-SE and is within about $30 \mathrm{~km}$ of GAFB at its closest point (Fig. 1). Within the upper $160 \mathrm{~m}$ (525 


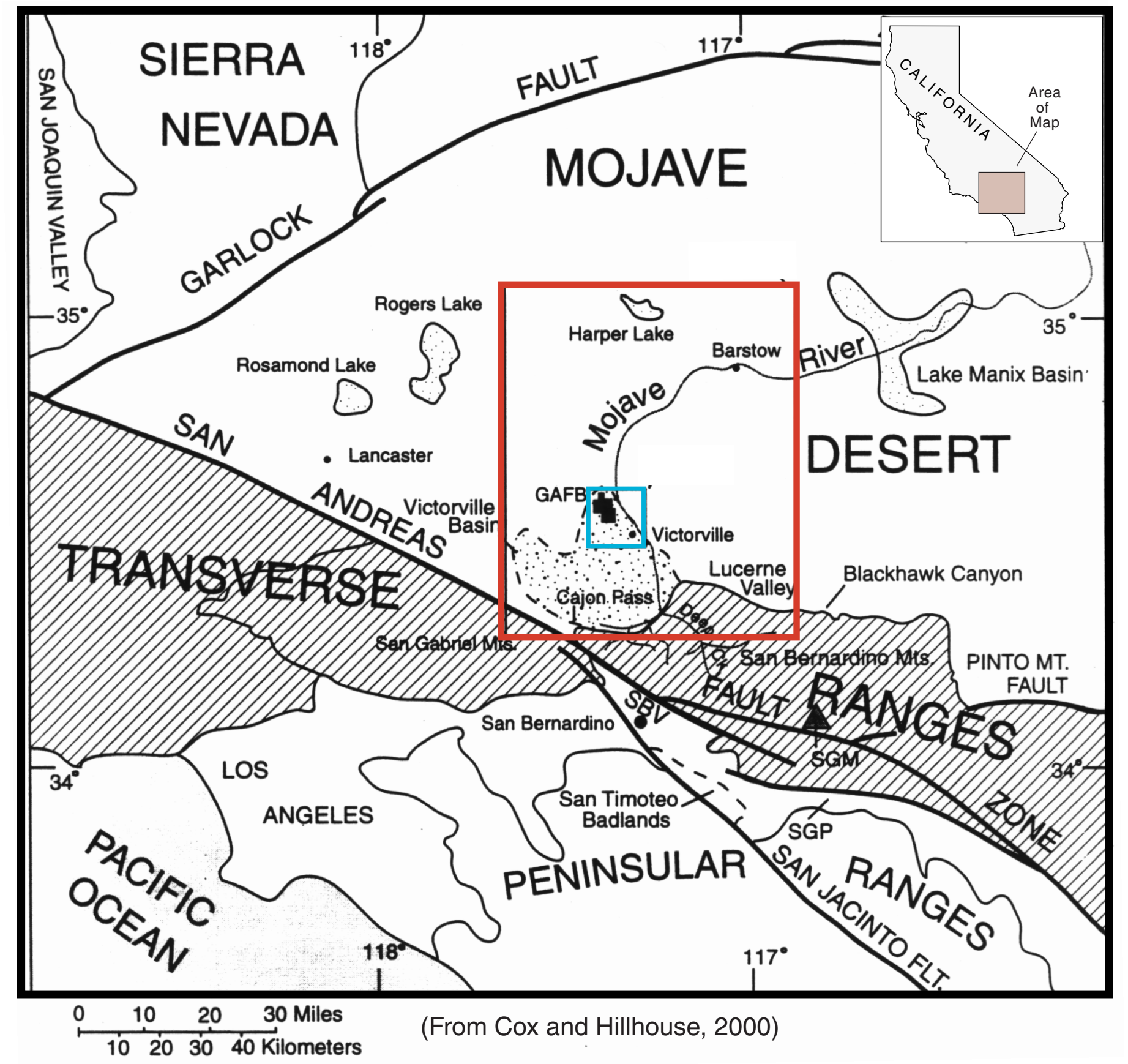

Fig. 1. Location map of the Mojave Desert region and parts of the surrounding geologic provinces in southern California (see inset). The principal fault zones in the area are also shown. The red box near the center of the map shows the general study area, and the smaller blue box shows the general study area of Cox and Hillhouse (2000). The black polygon within the blue box shows the outline of the former George Air Force Base (GAFB). 


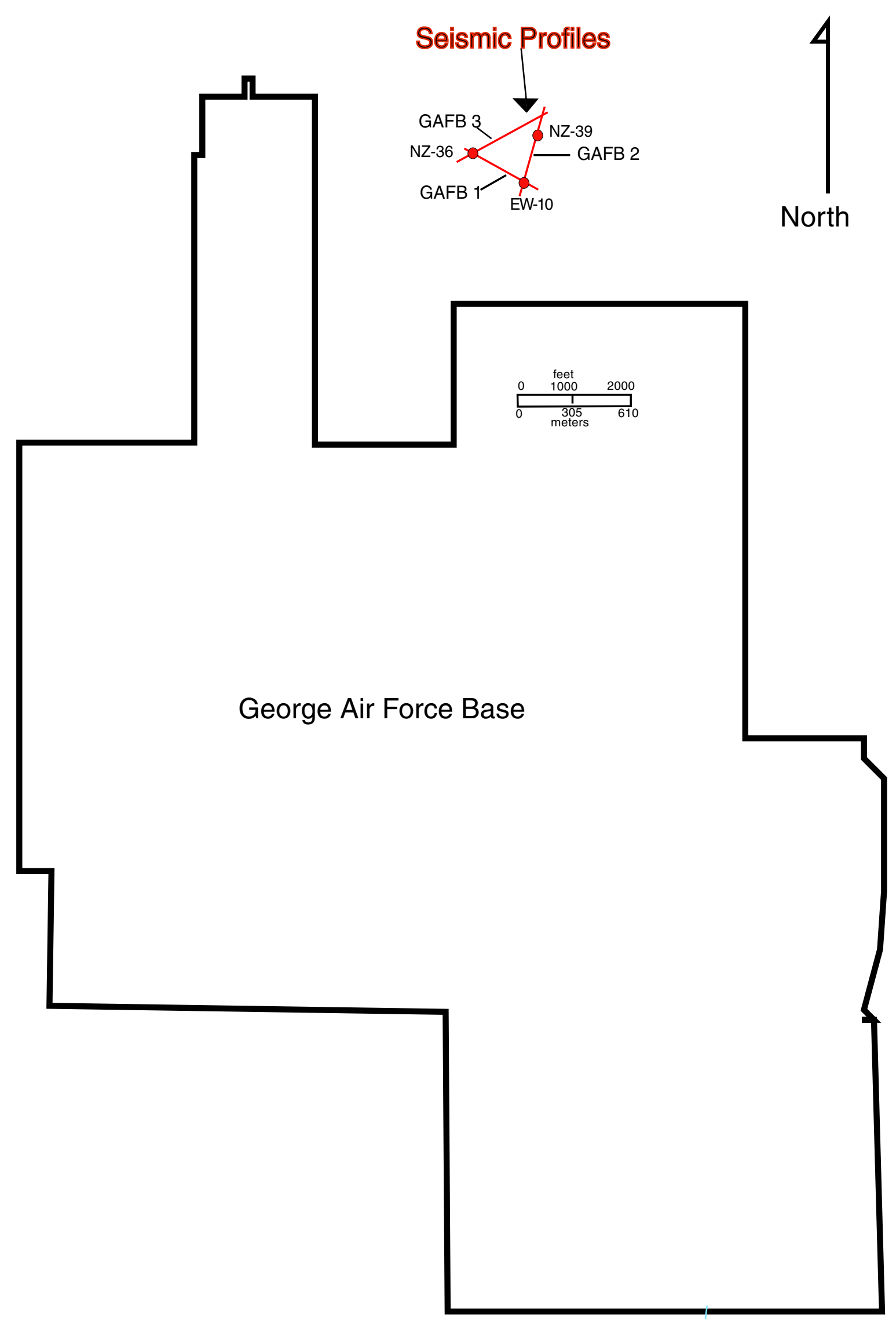

Fig. 2 Outline of the former George Air Force Base, with the location of seismic profiles (red lines) and wells (red dots) near the seismic profile. GAFB 1, 2, and 3 refer to the seismic profiles. NZ-36, NZ-39, and EW-10 refer to wells along the seismic profiles. 
$\mathrm{ft}$ ), the regional stratigraphy consists of Pliocene and Pleistocene (4.2 to less than 0.78 Ma) continental sediments, which can be categorized as three principal stratigraphic units, a lower unit, a middle unit, and a upper unit (Cox and Hillhouse, 2000; see Fig. 3).

\section{Lower Unit}

The stratigraphically lowest and chronologically oldest unit (unit \# 1, 4.2 to 1.18 $\mathrm{Ma}$ - Pliocene to early Pleistocene) is described as a lithic-arkose sand, silt, and polymitic pebble gravel unit that was deposited by a southward-flowing braided stream and associated alluvial fans (Cox and Hillhouse, 2000). Minor playa deposits are also apparent. The maximum thickness of the lower unit is undetermined, but some boreholes at GAFB have penetrated as deeply as $50 \mathrm{~m}$ into the lower unit without reaching its base. Cox and Hillhouse (2000) describe the physical condition of the lower unit as being weathered and oxidized, with authegenic calcium carbonate and clay minerals. They suggest that the silty sand deposits are poorly stratified and sorted, an important point for seismic imaging, as described below. Two thickly bedded, sandy facies are apparent within the lower unit. One unit consists of silty sand, and the other consists of a clean sand with pebbly gravel. Based on their content, Cox and Hillhouse (2000) suggest varying modes of deposition for the various facies. The deposits of clean sand and pebbly gravel accumulated in channels of a major southward flowing braided stream and possibly in washes of large alluvial fans. Deposits of the poorly sorted silty sands probably resulted from sheet floods in low-gradient fluvial or alluvial fan events. Thick beds of clayey silt and fine sand probably formed in small playas, and the wellstratifed silt and fine sand that cap the lower unit probably formed in a fluvio-deltaic environment. If the TCE has not migrated to lower depths, this stratigraphic sequence should not contain contaminants of interest to this study.

\section{$\underline{\text { Middle Unit }}$}

Cox and Hillhouse (2000) suggest that the middle lacustrine unit (unit \#2, Late Pliocene to early Pleistocene) consists of calcareous clay and silt, with lesser amounts of interlayered sand that was deposited in a shallow lake or wetland. The middle unit ranges in thickness from about 8 to $25 \mathrm{~m}$ at GAFB, with the thickest part of the unit near the southeast corner of GAFB, decreasing to the northwest. Physically, the unit is described as containing thick intervals of clay and clayey fine-grain silt with interlayered greenish and brownish sediments. In most wells, the middle unit is below the aquifer or its immediate aquitard. For purposes of ground-water flow and TCE migration, the presence or absence of this layer is important.

\section{Upper Unit}

The stratigraphically highest and chronologically youngest unit (unit \# 3 Pleistocene to Present) is described as a compositionally homogeneous fluvial unit consisting of a sequence of granititc sand, silt, and gravel that was deposited by a northwest-flowing, ancestral Mojave River. The upper unit ranges in thickness from about 4.5 to $110 \mathrm{~m}$, with the thickest part of the unit located near the southwest corner of GAFB, thinning to the north and west margins of the base. Cox and Hillhouse (2000) describe the upper unit as consisting of four distinct lithofacies, each consisting of loose to weakly consolidated, yellow-brown and olive-brown sediments. Two of the facies are apparently thickly bedded sand (one silty fine sand and the other pebbly coarse sand) that are interlayered throughout the unit. A third facies consists of thinly bedded fine sand, silt, and sparse clay. A fourth facies includes beds of pebble and coarse gravel, which are 
interlayered with thickly bedded, fine and coarse sand near the top of the unit. Cox and Hillhouse (2000) refer to the upper unit as the "George Surface", which is capped by a fossil soil profile containing well-developed argillic and calcic horizons. The upper unit contains the aquifer system that is presumed to transport the TCE contaminant in the subsurface. 
Basic Stratigraphic Units

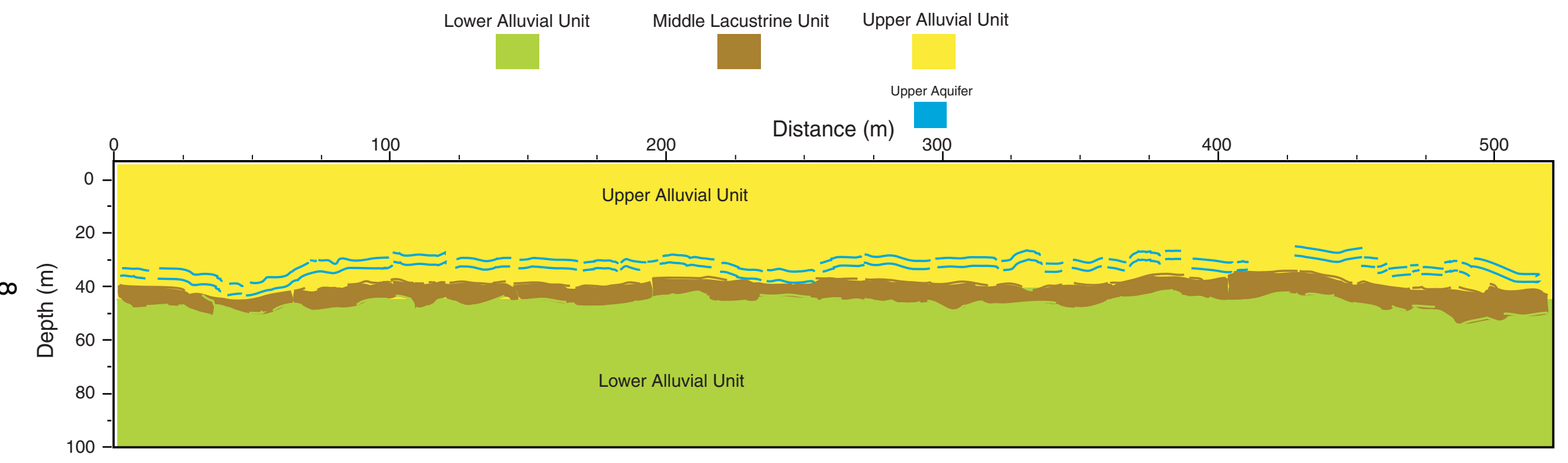

Fig. 3 Basic stratigraphic units in the George Air Force Base area, as defined by Cox and Hillhouse (2000). The approximate location of the upper aquifer is shown within the Upper Alluvial Unit, as determined from boreholes. 


\section{Tectonism and Regional Faulting}

The upper and lower units were apparently deposited by opposite-flowing rivers. Cox and Hillhouse (2000) suggest that the change in flow directions was caused byregional contraction along an anticline located north of GAFB. Presumably, the middle unit resulted from a shallow lake that formed as the contraction and folding of the region occurred. This regional tectonism was undoubtedly related to the movement on the San Andreas Fault system, as numerous northwest-oriented faults are evident in the region. Cox and Hillhouse (2000) also suggest the existence of vertical faulting near the southwest margin of GAFB, where strata in one of the boreholes was consistently elevated relative to equivalent strata in three other boreholes. To the immediate southeast of GAFB, Cox (pers. comm, 2000) mapped northwest-oriented lineaments that trend toward GAFB. Several of these lineaments were confirmed to be faults where they were imaged with high-resolution seismic methods (Catchings et al., 2000). This apparent faulting and its orientation may have important implications for the locating contaminants within the ground water flow system at GAFB.

\section{Seismic Survey}

Three seismic reflection/refraction profiles were acquired in July 1999 by the US Geological Survey's High-Resolution Seismic Imaging Group. The separate seismic profiles (labeled GAFB 1, GAFB 2, and GAFB 3) collectively formed a triangle (Fig. 2). The acquisition parameters for each profile are shown in Table 1. The triangular shape of the survey allowed structure and stratigraphy from each separate profile to be correlated among all the profiles. At least one well with an available lithologic log was located along each profile. Wells NZ-36 and EW-10 were located along profile GAFB 1, wells EW-10 and NZ-39 were located along profile GAFB 2, and well NZ-36 was located along profile GAFB 3. The lithologic logs from these wells allow us to correlate reflecting horizons observed in the seismic data with known lithology. Approximately 2 seconds of data were recorded on four Geometrics Strataview ${ }^{\mathrm{TM}}$ RX 60 seismographs, each with 60 active channels. The data were stored on the hard drive of the Strataview computers during field acquisition and were later downloaded to 4-mm tape for permanent storage in SEG-Y format.

Sensors consisted of $24040-\mathrm{Hz}$, single-element, Mark Products L-40A ${ }^{\mathrm{TM}}$ vertical geophones, spaced at 2-m increments along the profile. Seismic sources (shots), located at about 0.3 -m depth, were generated by a BETSY Seisgun ${ }^{\mathrm{TM}}$ using 8 -gauge shotgun blanks. Shots were also spaced at 2-m increments along the profile and were co-located (1-m lateral offset) with the geophones. Shot timing was determined electronically at the seismic source when a hammer, used to trigger the seisgun, electrically closed contact with the BETSY Seisgun ${ }^{\mathrm{TM}}$, sending an electrical signal to the seismograph.

Table 1. Acquisition parameters for the three SCIA (GAFB) seismic profiles. Distance is relative to the first shot point.

\begin{tabular}{|l|l|l|l|l|l|l|}
\hline Profile \# & Orientation & $\begin{array}{l}\text { Length of } \\
\text { geophone } \\
\text { Profile }(\mathrm{m})\end{array}$ & $\begin{array}{l}\text { Length of } \\
\text { shot Point } \\
\text { Profile }(\mathrm{m})\end{array}$ & $\begin{array}{l}\text { No. of } \\
\text { shots }\end{array}$ & $\begin{array}{l}\text { No. of } \\
\text { CDPs }\end{array}$ & $\begin{array}{l}\text { Maximum } \\
\text { fold }\end{array}$ \\
\hline GAFB 1 & NW-SE & 464.75 & 464.77 & 226 & 238 & 226 \\
GAFB 2 & S-N & 697.44 & 521.44 & 257 & 609 & 174 \\
GAFB 3 & SW-NE & 579.97 & 580.01 & 284 & 560 & 174 \\
\hline
\end{tabular}




\section{Data Acquisition}

In seismic reflection images, artifacts can be mistaken for structure if geophones and/or shots locations have significant elevation and lateral variations that are not accounted for in processing the data. Deviations from a linear array of geophones or shots can also create artifacts in the data. To properly account for such variations in geometry, each shot point and geophone location was surveyed using an electronic distance meter (EDM) or GPS with theoretical accuracies of a few centimeters. The geometry data are presented in Appendixes 1, 2, and 3.

\section{GAFB 1}

Geophone elevations along GAFB 1 varied vertically by less than $4.2 \mathrm{~m}$ over a distance of about $465 \mathrm{~m}$ (Fig. 4), and the horizontal alignment of geophones varied from a linear array by about $0.5 \mathrm{~m}$ (Fig. 5) over the same distance. Variations in shot-point elevations (Fig. 6) and linearity of shot points (Fig. 7) are similar to those of the geophones. These minor variations in shot and geophone elevations and linearity suggest that there is little need for statics corrections, however, static corrections were applied for greater accuracy. A total of eight shot-point locations were not used along the profile due to cultural features.

Fold (the theoretical number of times a reflection occurs at a given subsurface location) along profile GAFB1 was smoothly varying because we used a stationary recording array (Fig. 8). Maximum folds of about 226 was obtained in the center of the seismic profile and decreased to about 1 near the ends of the profile. Because maximum folds were in the middle of the seismic profile, the most reliable reflection image for the deeper structure should theoretically be near the center of the profile. However, for the depth range of interest to this study (upper $100 \mathrm{~m}$ ), reflection images should be reliable along the entire profile. The shot and geophone setup along GAFB 1 suggests that there should not be artifacts in the data due to geometry.

\section{GAFB 2}

Geophone elevations along GAFB 2 varied by less than $4 \mathrm{~m}$ over a distance of about $579 \mathrm{~m}$ (Fig. 9), and the horizontal alignment of the geophones varied from a linear array by less than $1.75 \mathrm{~m}$ (Fig. 10) over similar distances. Variations in shot-point elevation (Fig. 11) and linearity (Fig. 12) along profile GAFB 2 are similar to those of the geophones. A total of five shot points were not utilized along profile GAFB 2 because of cultural features or logistical limitations.

Fold was not smoothly varying because the recording array was not stationary for all shots (Fig. 13). We moved the some of the sensors northeastward along the profile as the seismic sources approached the northeastward end of the actively recording array. Maximum folds ranged from about 174 between meters 174 and 232, about 117 between meters 290 and 365, about 83 between meters 408 and 524, and decreased linearly to about one near the ends of the profile. However, signal strength was more than adequate to image the depths of interest along the entire profile. We anticipate and observe no artifacts in the data due to the geometrical setup of the seismic profile.

\section{GAFB 3}


Geophone elevations varied by about $4.5 \mathrm{~m}$ along the $580 \mathrm{~m}$-long GAFB 3 profile (Fig. 14), and the linearity of the geophone array varied by less than $2.5 \mathrm{~m}$ over that distance (Fig. 15). The vertical and lateral variations in shot-point locations are similar to those of the geophones (Figs. 16 and 17, respectively). A total of seven shot points were not utilized due to cultural features and logistical limitations. A maximum fold of 172 was obtained near the center of the profile (Fig. 18). The geophone setup of profile GAFB 3 suggests that there should not be artifacts in the data due to geometry.

\section{Seismic Imaging Methods}

Both reflection and refraction data were acquired simultaneously using a shootthrough configuration, whereby shots are fired through the stationary recording array along long segments of the profile. This type of data acquisition has numerous advantages over conventional seismic data acquisition methods. In particular, two 


\section{Profile GAFB 1}

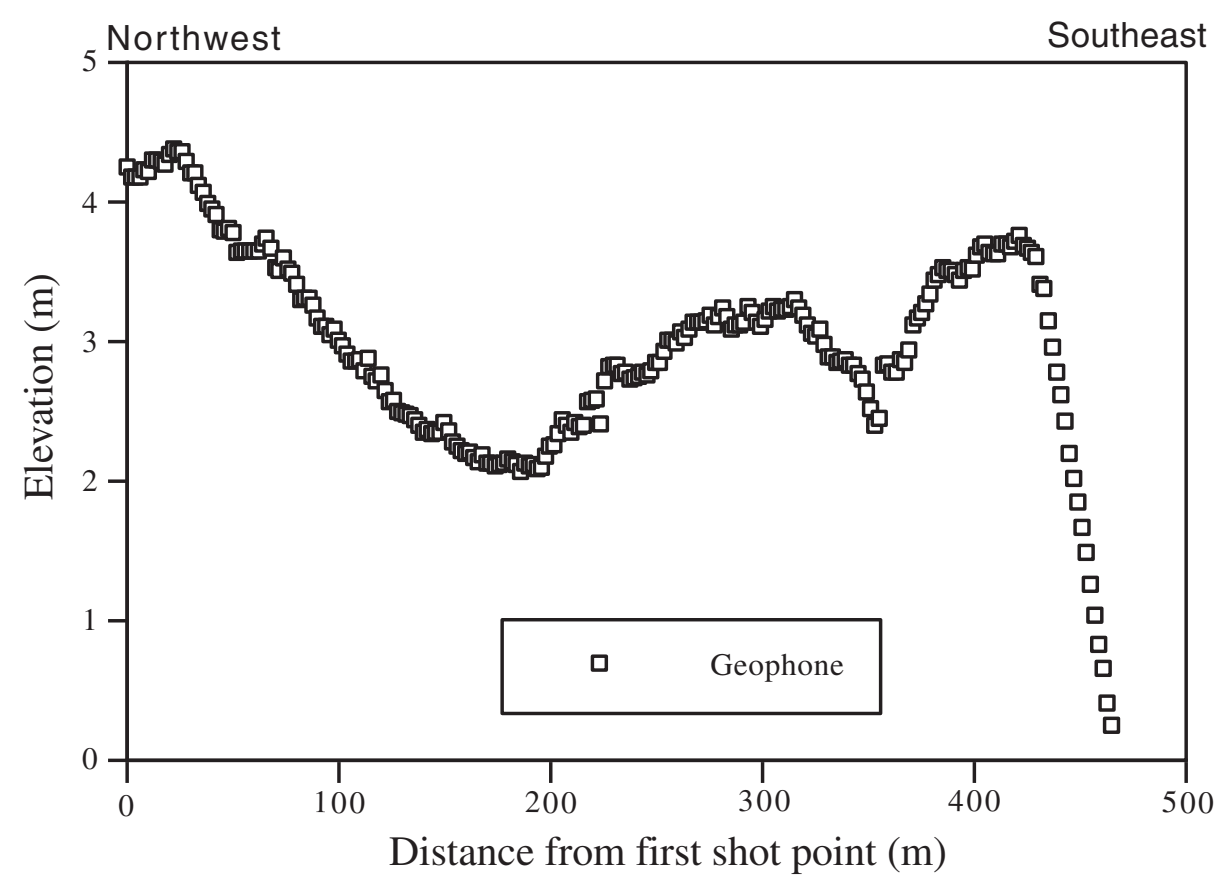

Fig. 4. Geophone elevation along Profile GAFB1. Elevation is relative to the topographically lowest shot point along the profile.

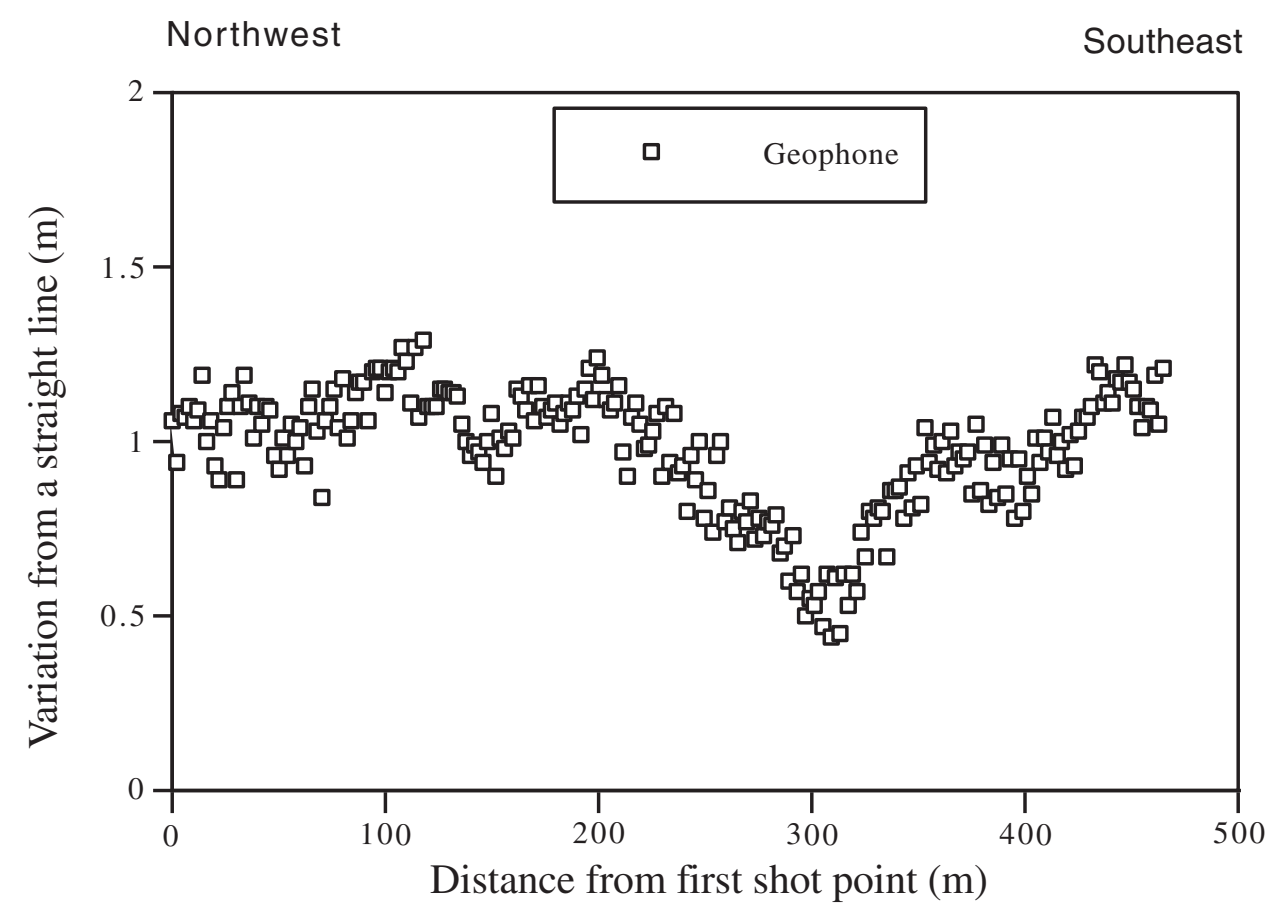

Fig.5. Geophone variation from a straight line connecting the first and last geophone along Profile GAFB 1 


\section{Profile GAFB 1}

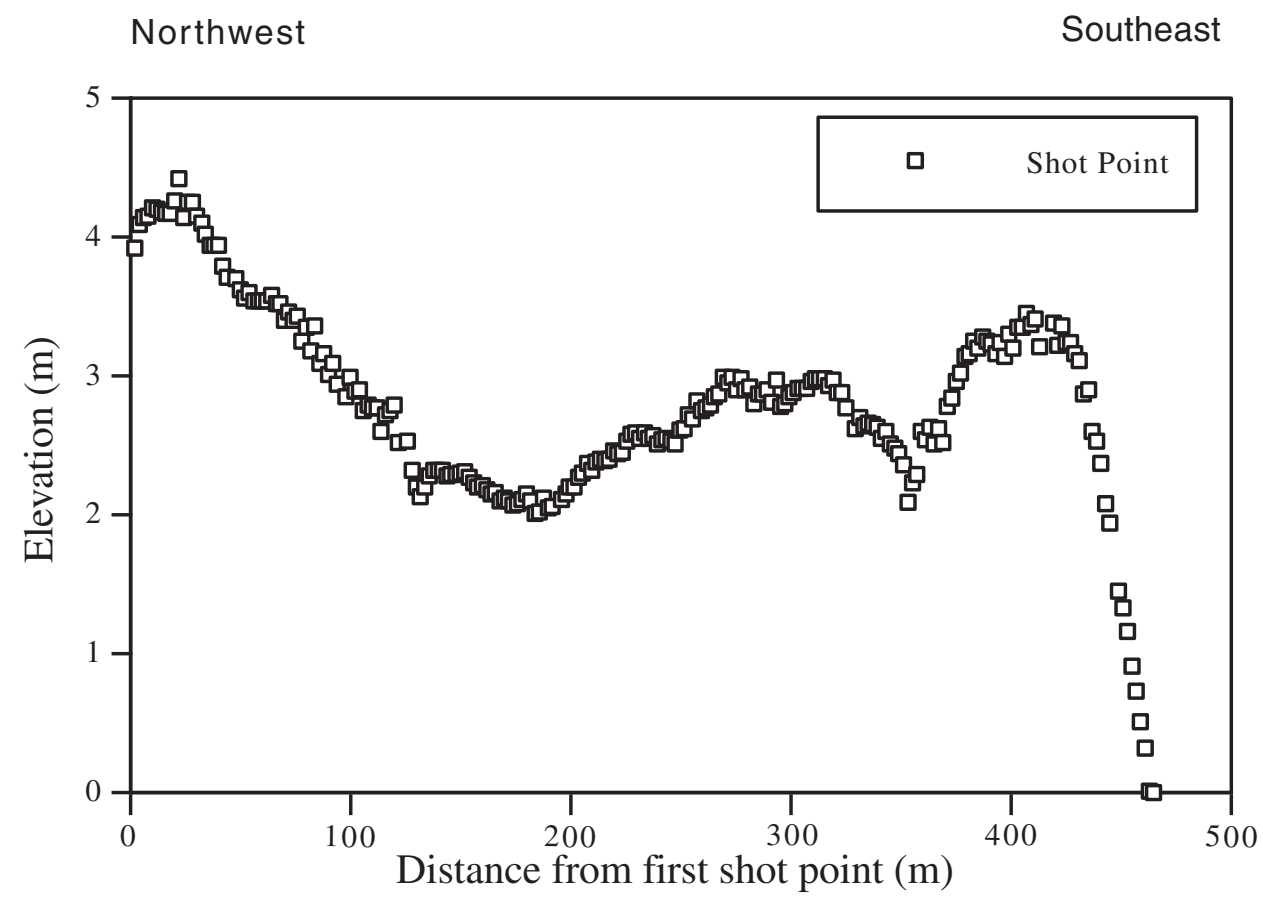

Fig. 6. Shot point elevation along Profile GAFB1. ELevation is relative to the topographically lowest shot point along the profile.

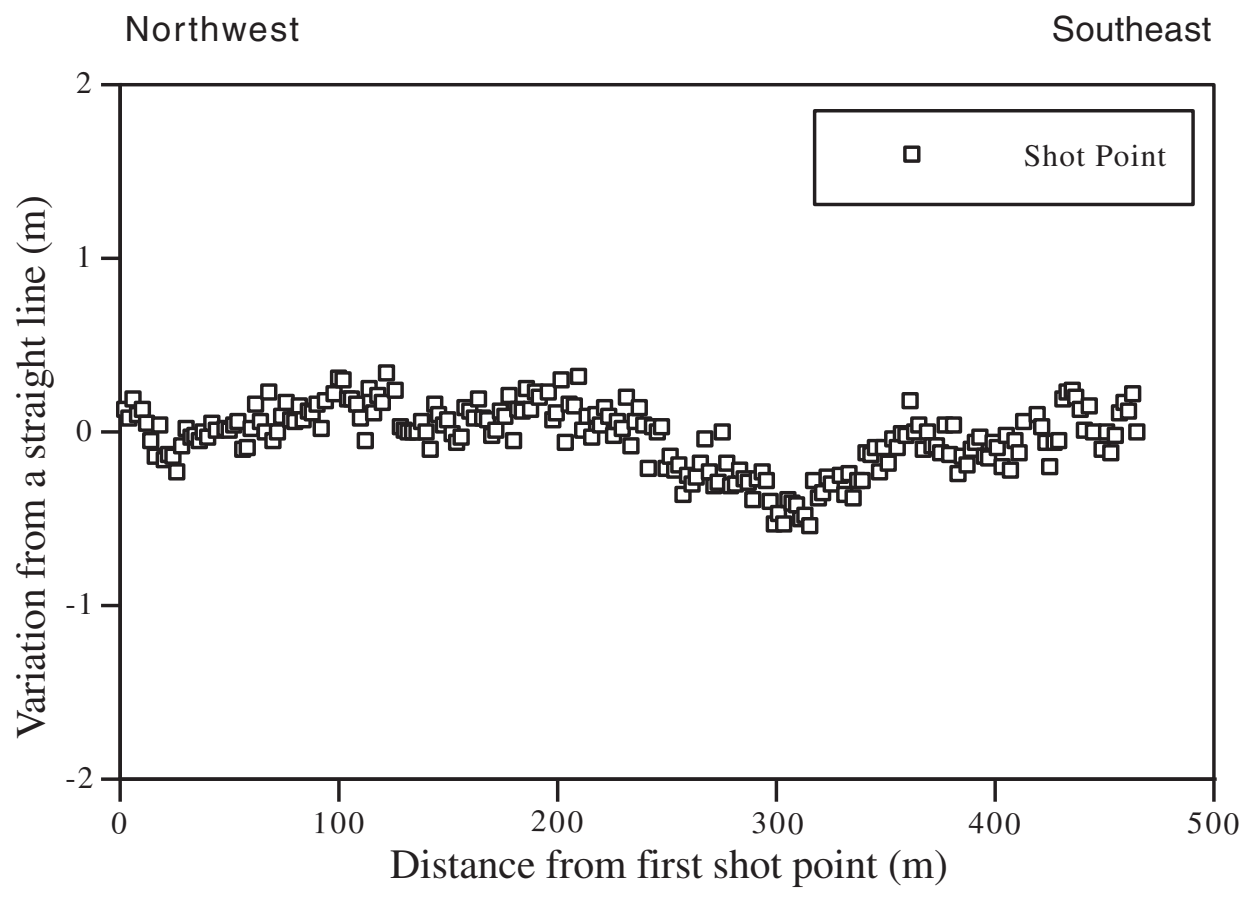

Fig. 7. Shot point variation from a straight line connecting the first and last shot points along Profile GAFB 1. 
Profile GAFB 1

Northwest

Southeast

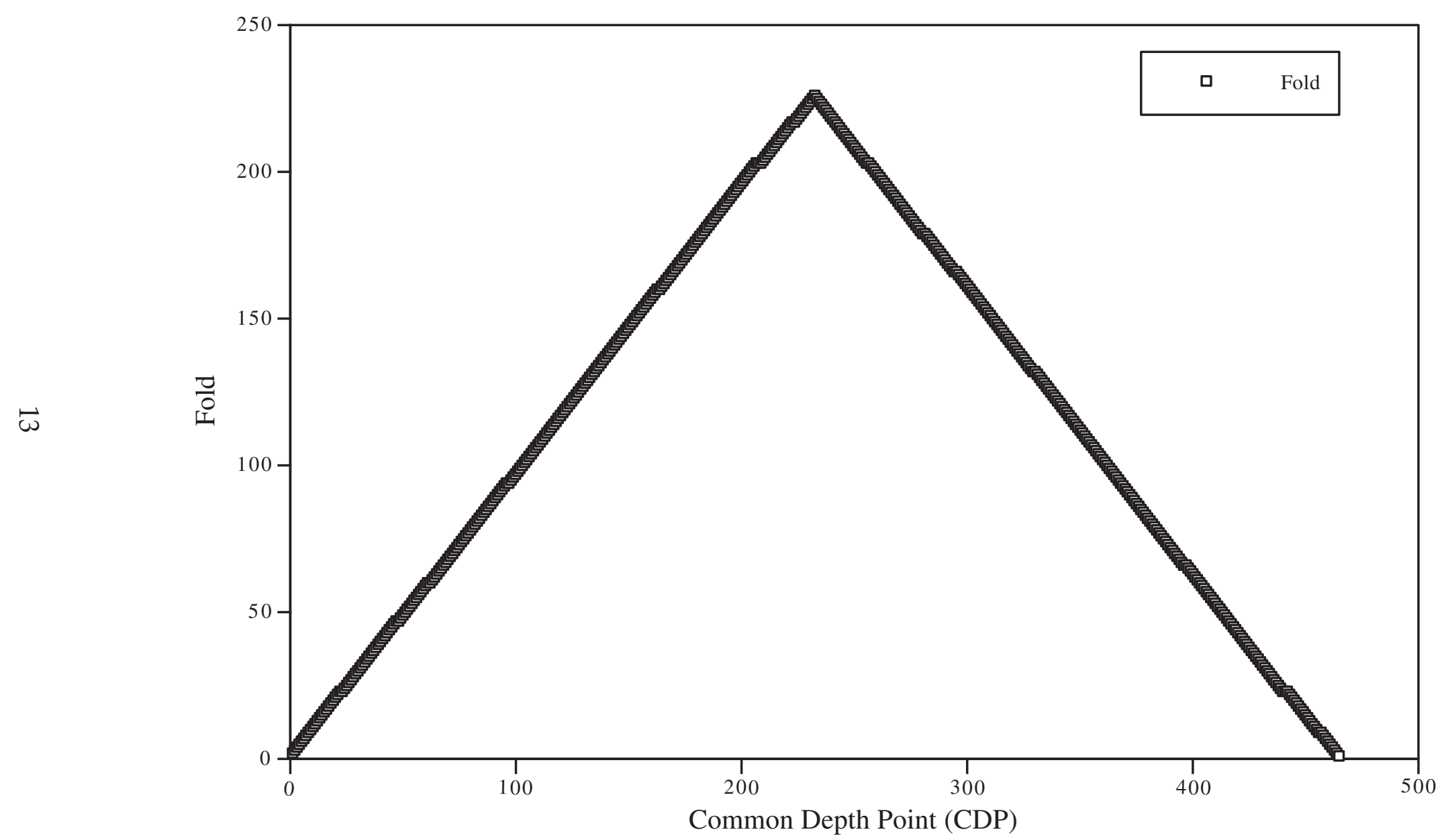

Fig. 8. Fold as a function of Common Depth Point (CDP) along Profile GAFB 1 


\section{Profile GAFB 2}

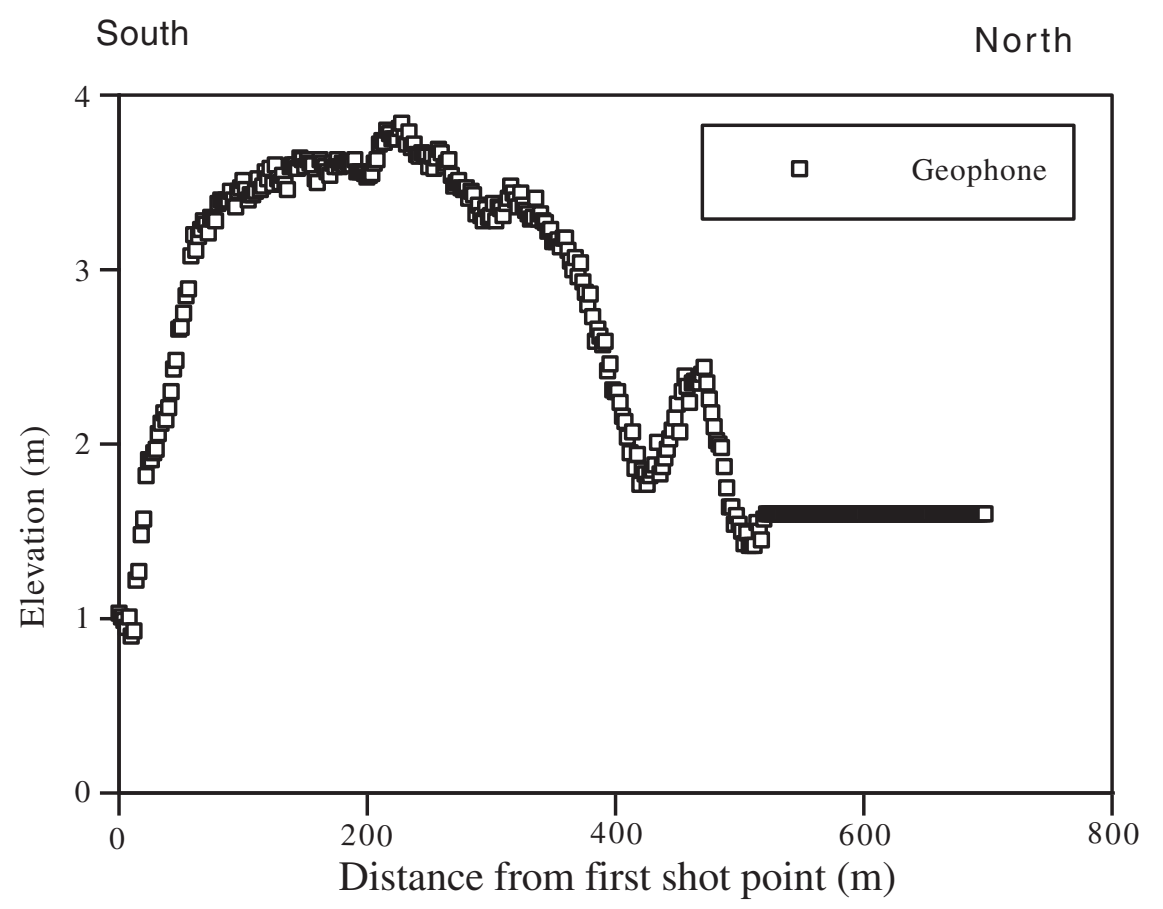

Fig. 9. Geophone elevation along Profile GAFB 2. Elevation is relative to the topographically lowest shot point along GAFB 2.

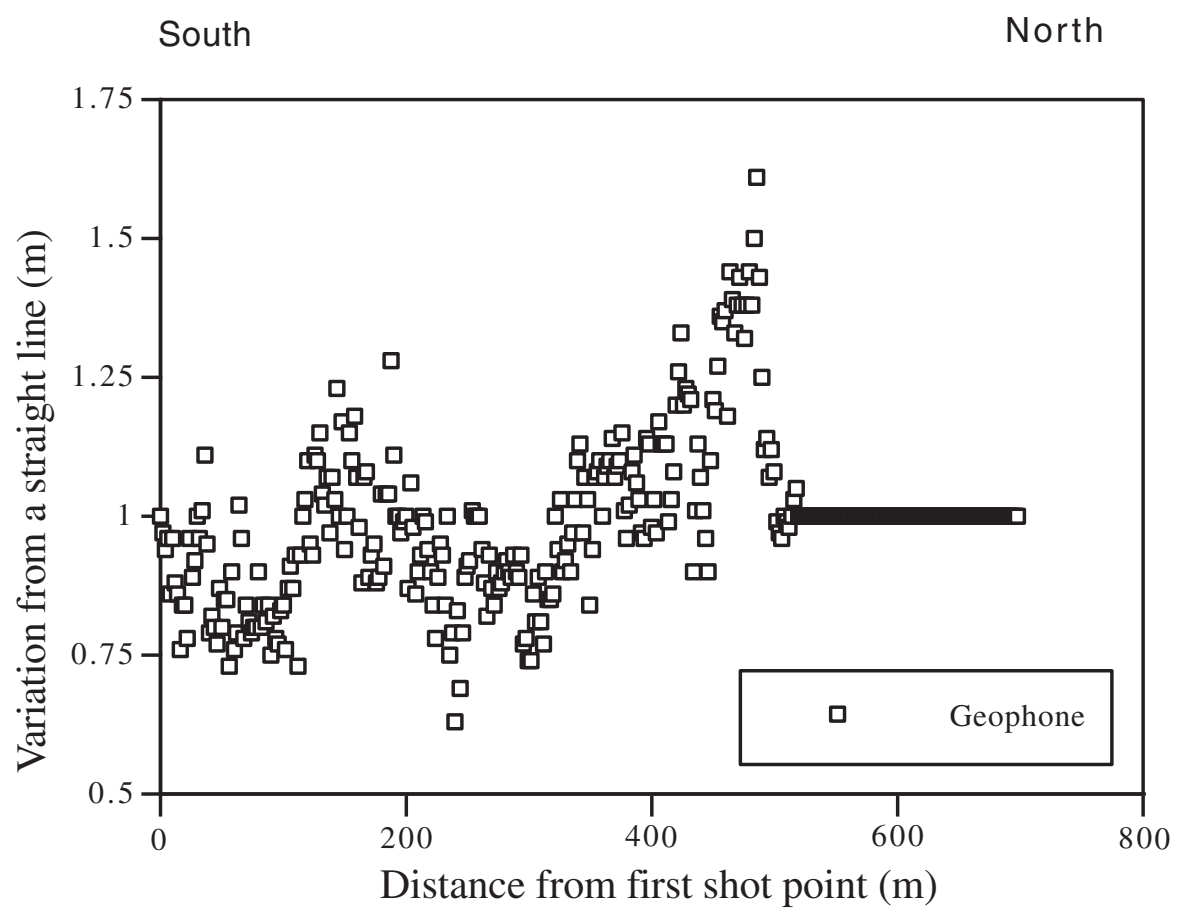

Fig.10. Geophone variation from a straight line connecting the first and last geophone along profile GAFB 2. 


\section{Profile GAFB 2}

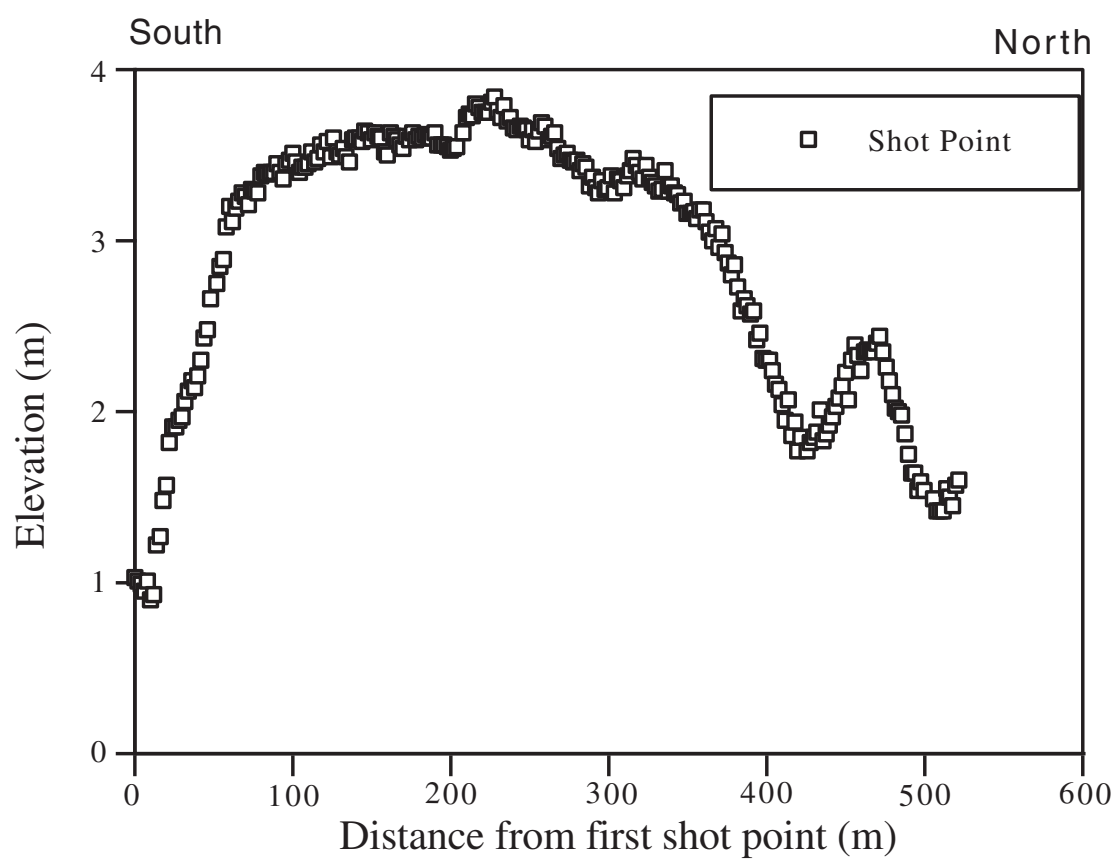

Fig. 11. Shot point elevation along Profile GAFB 2. Elevation is relative to the topographically lowest shot point along the profile.

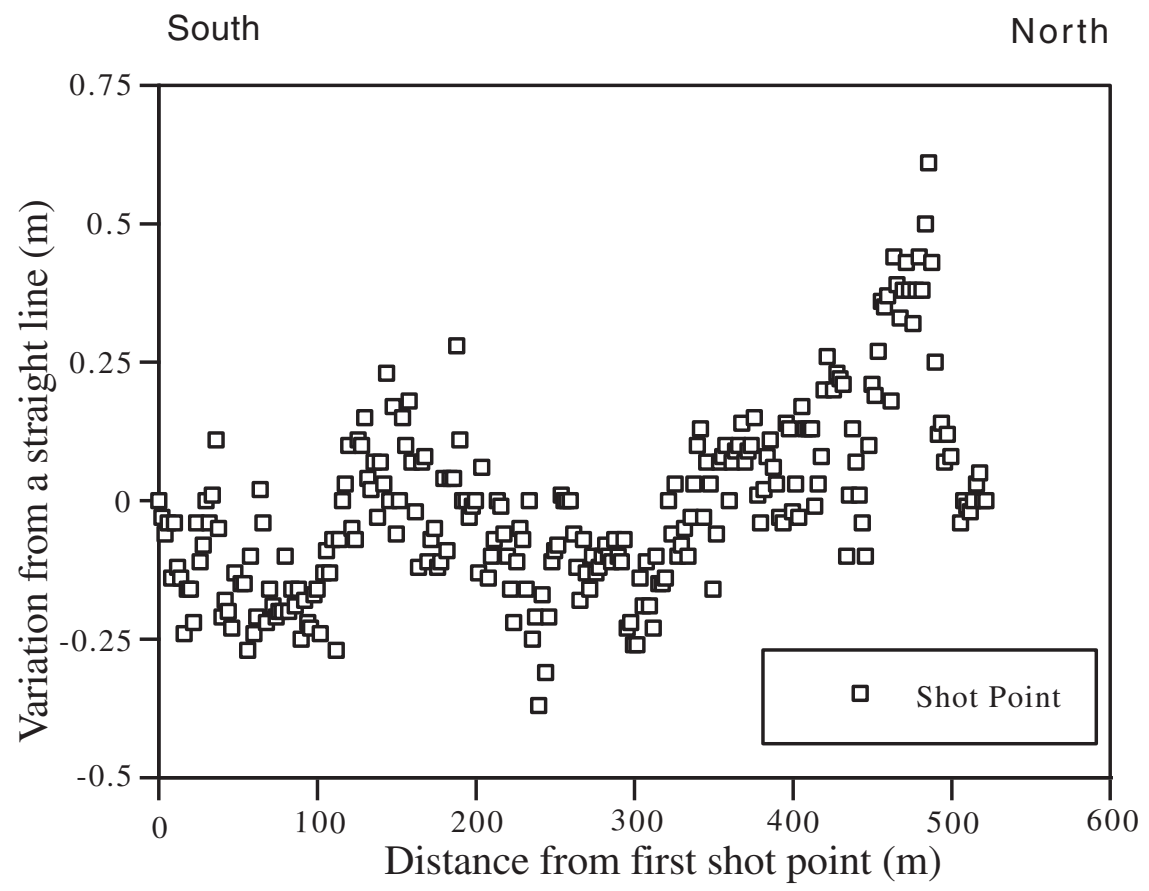

Fig. 12. Shot-point variation from a straight line connecting the first and last shot point along Profile GAFB 2. 
Profile GAFB 2

South

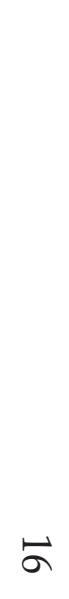

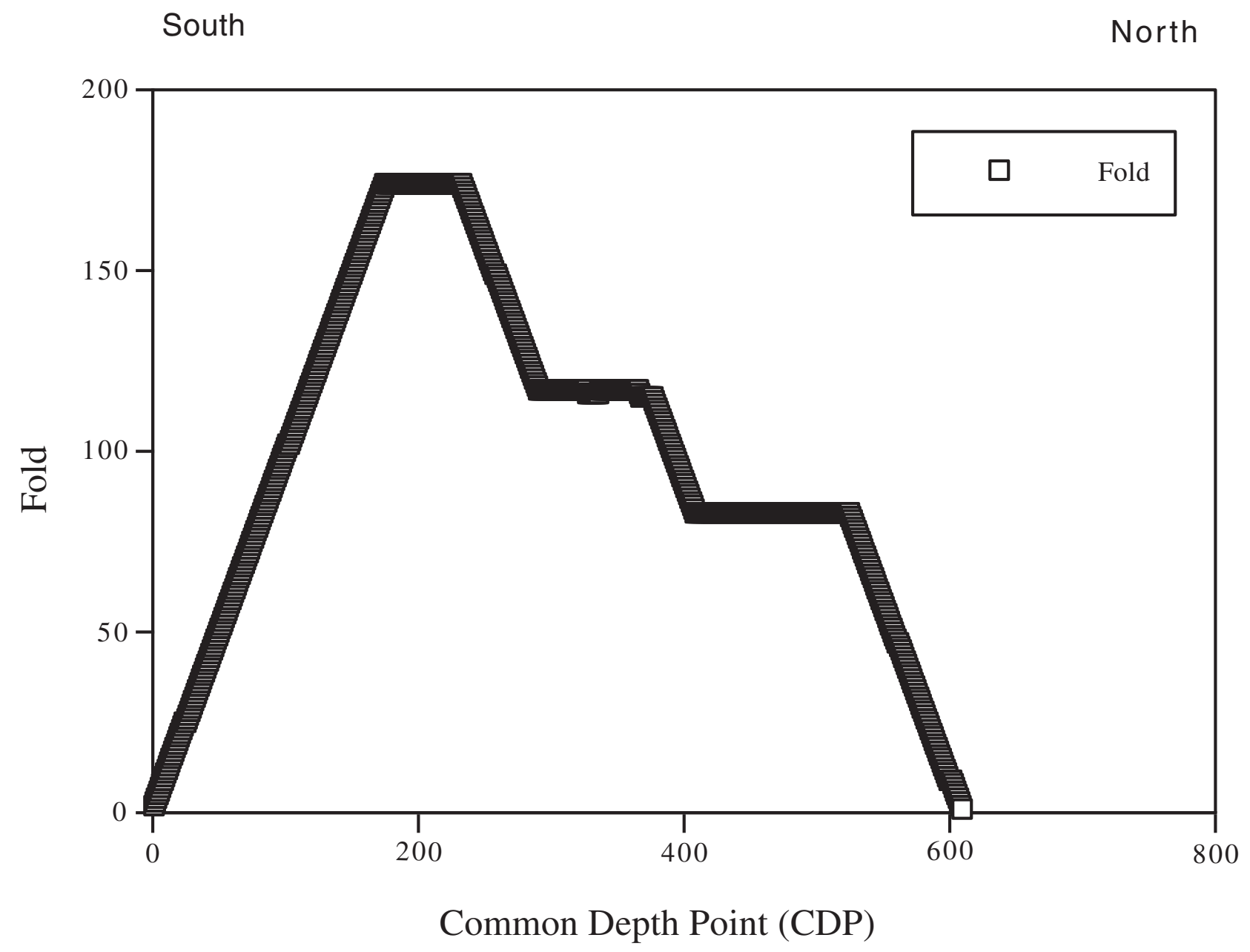

Fig. 13 Fold as a function of CDP (Common Depth Point) along Profile GAFB 2 


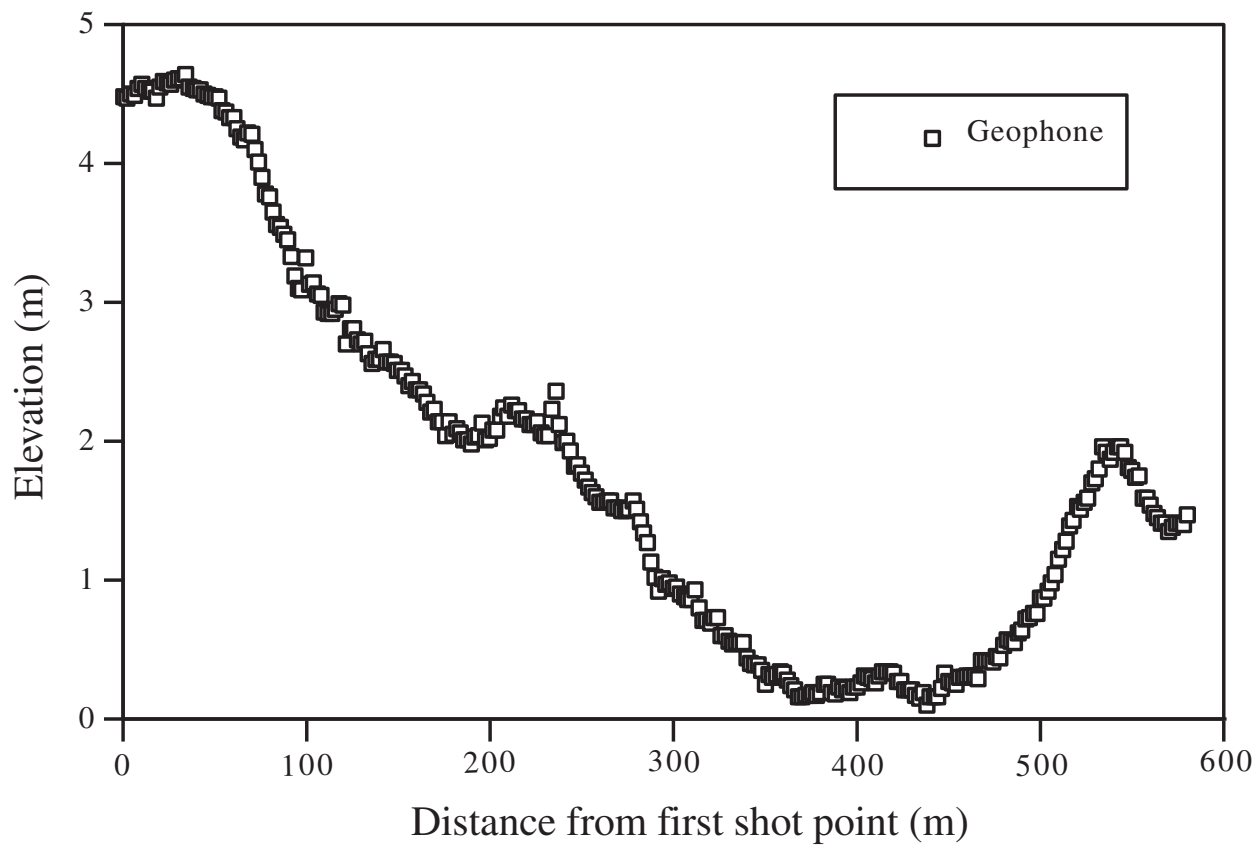

Fig. 14. Geophone elevation along Profile GAFB 3. ELevation is relative to the topographically lowest shot point along the profile.

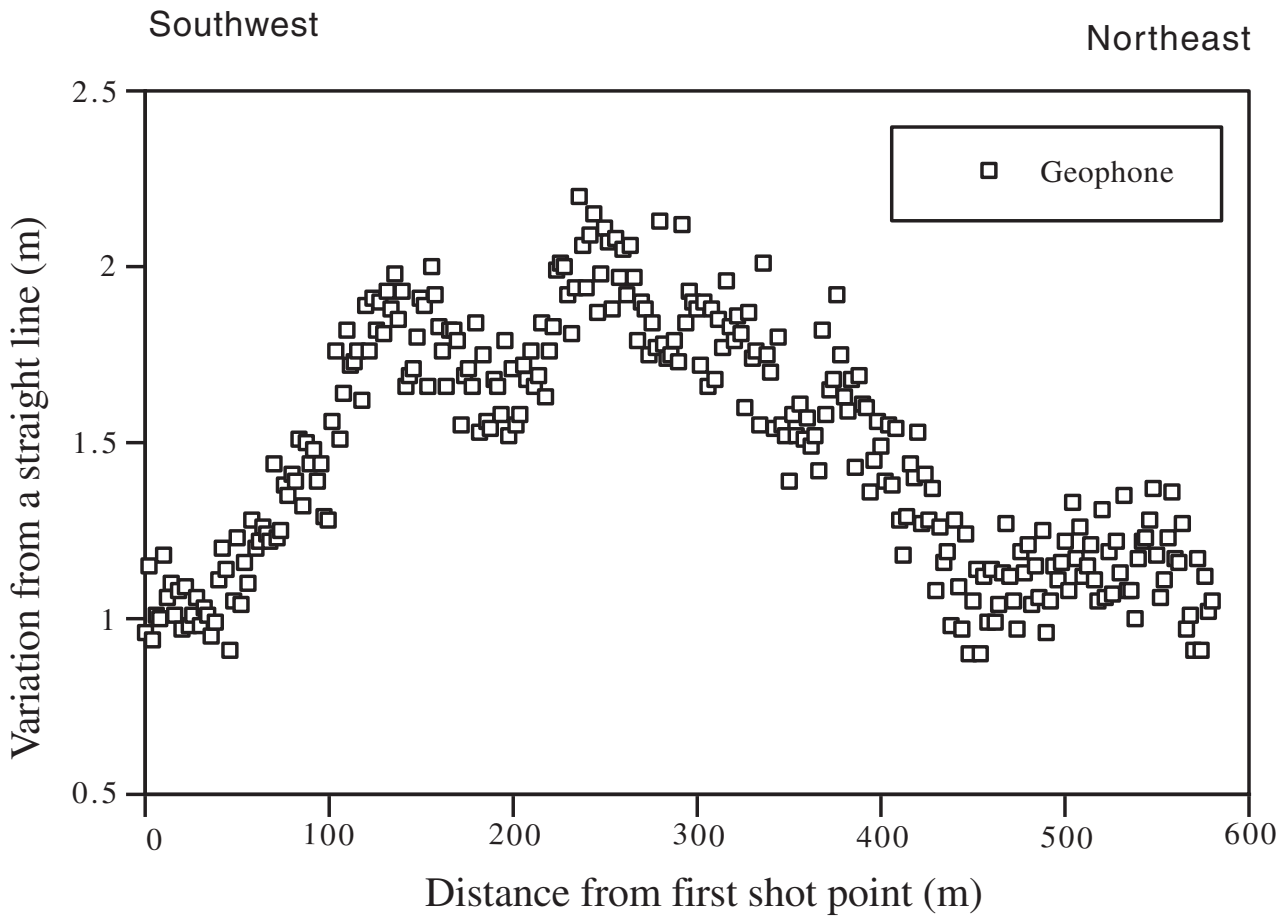

Fig.15. Geophone variation from a straight line connecting the first and last shot points along Profile GAFB 3. 


\section{Profile GAFB 3}

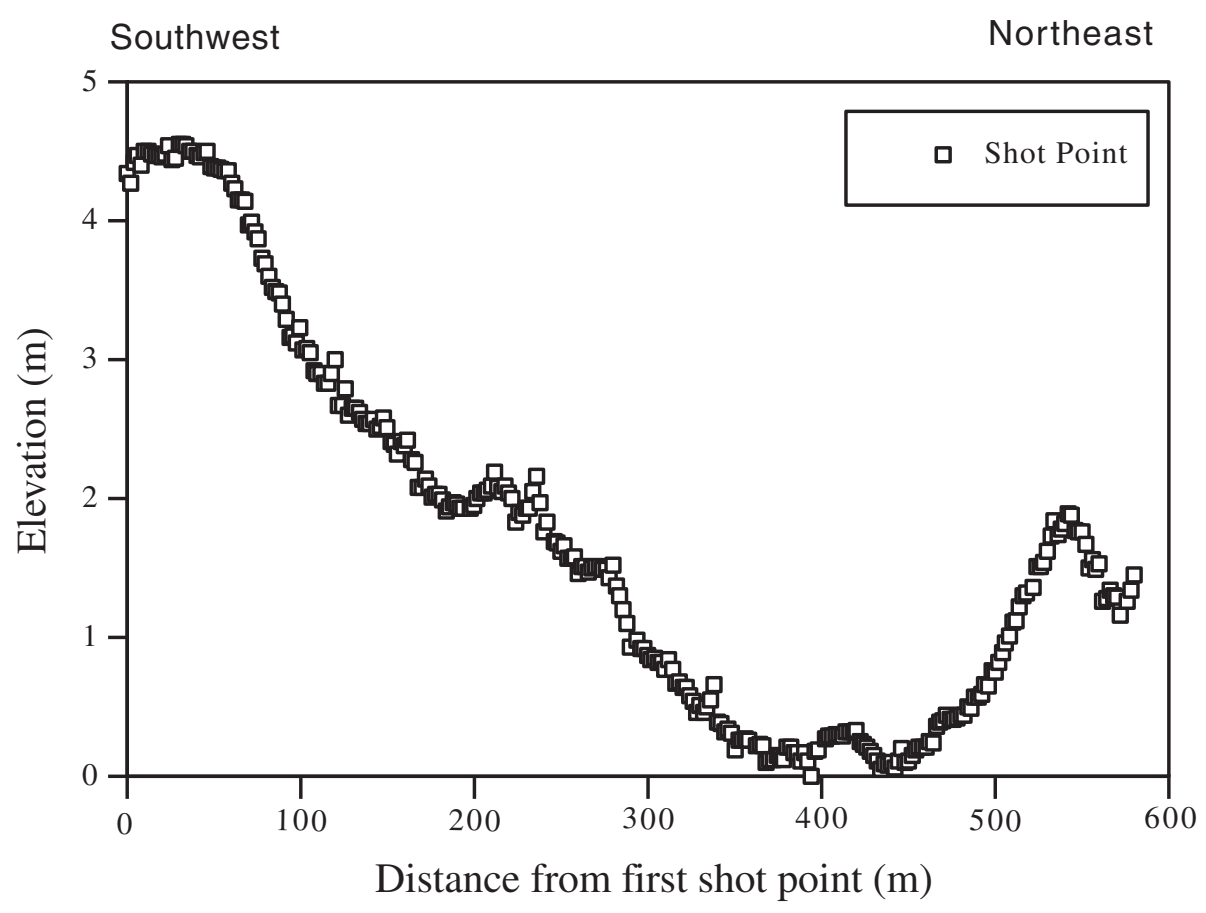

Fig. 16. Shot point elevation along GAFB 3. ELevation is relative to the topographically lowest shot point along the profile.

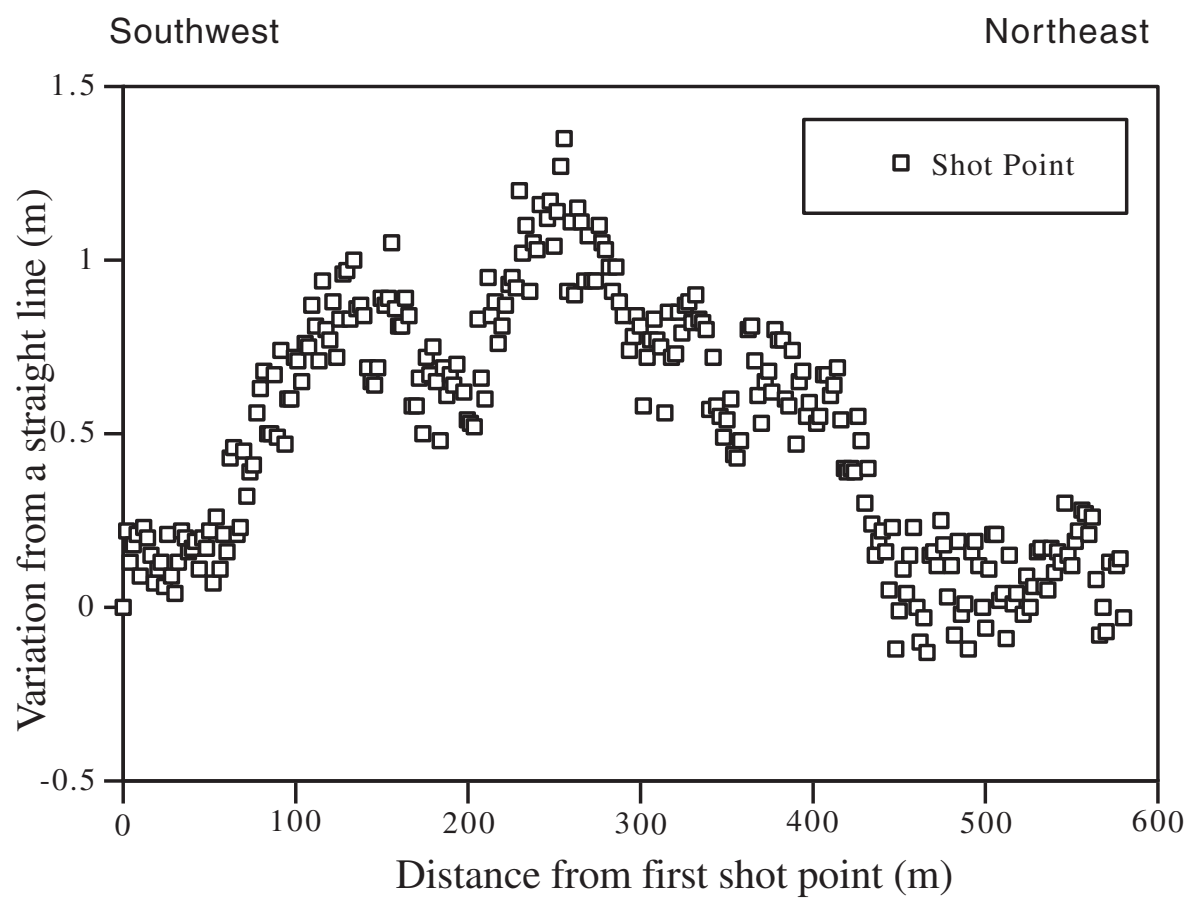

Fig. 17. Shot-point variation from a straight line connecting the first and last shot point along profile GAFB 3. 
Profile GAFB 3

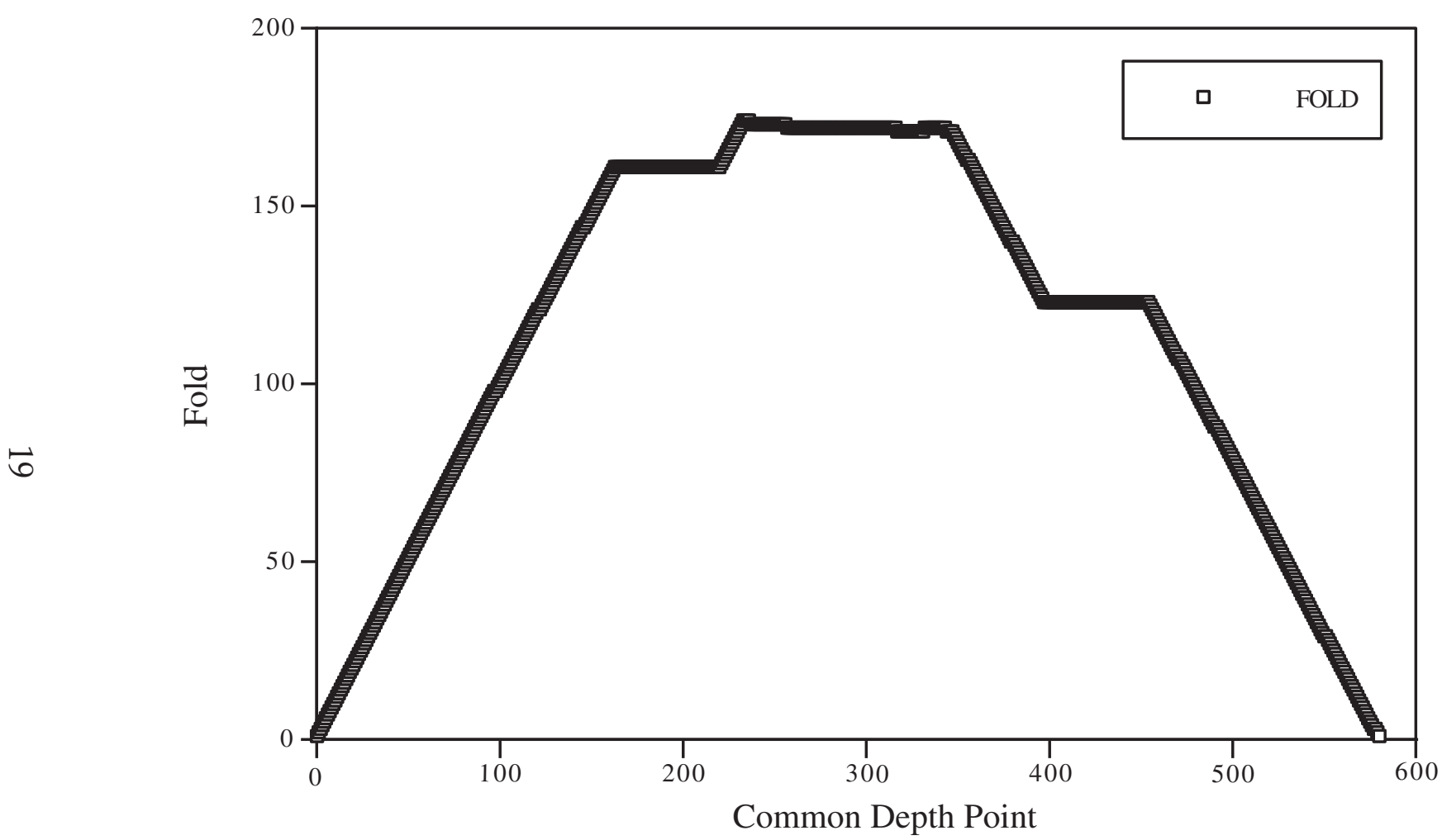

Fig. 18 Fold as a function of CDP (Common Depth Point) along Profile GAFB 3. 
separate images of the subsurface are generated with the same seismic data. Below, we describe the processing methods utilized for each type of data.

\section{Seismic Refraction}

Seismic refraction methods measure the velocity at which seismic waves travel through the subsurface. The measured velocity depends on the properties of the subsurface materials. For example, seismic waves travel faster in solid rock than in sediments, faster in clay than in sand, and faster in water-saturated sediments than in dry sediments.

Our surface-based seismic refraction technique uses the same surface-based seismic source and sensors described in the reflection method. The sensors measure the time it takes for the refracted seismic energy to propagate from the source to each sensor. By knowing the distance between sensors, the velocity with which seismic energy propagates through the subsurface layers can be calculated. Using a tomographic method (Hole, 1992), we make these measurements many times for a given area in the subsurface, thereby yielding a highly accurate measurement of the subsurface velocity structure.

The greatest variation in seismic velocities generally occurs near the surface, with lateral variations in composition and in physical state. These lateral variations in velocity make it difficult to develop a seismic reflection image using a stacking process (adding the seismic signal from each shot into a single seismic section). Because stacking is critical to obtaining a clear reflection image of the subsurface, detail knowledge of nearsurface variations in velocity is needed. Thus, the velocity data provide indications of the subsurface materials and their physical states, and they independently constrain the reflection images.

\section{Seismic Reflection}

Seismic reflection methods use reflected seismic energy to provide a visual image of stratigraphic layers in the subsurface. Surface-based seismic reflection imaging techniques use a surface energy source (small charges, vibrators, hammer, etc.) to impart seismic energy into the subsurface. Seismic energy travels spherically from the source until it encounters interfaces between two stratigraphic horizons. At each interface, part of the seismic energy is reflected back to the surface, and the remainder of the seismic energy penetrates through the interface to deeper horizons. The seismic energy that is reflected back to the surface is sensed by numerous sensors at the surface and is recorded by seismographs. The recorded seismic data are then computer processed to generate a seismic image that resembles a geologic cross section.

Resolution of layers depend on a combination of source spacing, sensor spacing, the frequency content of the induced and recorded signal, the velocity of subsurface media, the density at layer boundaries, and the thickness of those layers. For example, in a high-frequency image, separate reflections may be observed at the top and bottom of a layer of fixed thickness. On a slightly lower-frequency image, however, the same layer may produce only one reflection, and on a very low-frequency image, the same layer may not produce a reflection event at all. The other factors that influence resolution would similarly affect which reflection events are observed on the seismic image.

For most seismic images, it is difficult to determine which reflection event on the seismic image corresponds to which specific stratigraphic horizon without additional 
data. Therefore, where possible, we correlate individual reflection events with known stratigraphic horizons observed from boreholes, and because there was a reflection event corresponding to each meter along the seismic profiles, stratigraphic horizons can be mapped laterally.

\section{Data Analysis}

\section{Seismic Refraction Velocity Analysis}

Velocities were measured at depths ranging from about $1 \mathrm{~m}$ below ground surface (bgs) to about $30 \mathrm{~m}$ bgs. For greater depths, velocities needed for seismic reflection stacking were determined using semblance, parabolic methods, and apriori knowledge of the local geology, derived by combining borehole and empirical data. We also used the inversion-derived velocities to convert the reflection time images to depth images and to migrate the seismic reflection images.

\section{Seismic Reflection Processing}

Seismic reflection data processing was accomplished on a Sun Sparc $20^{\mathrm{TM}}$ computer using an interactive seismic processing package known as ProMAX ${ }^{\mathrm{TM}}$. The following steps were involved in data processing:

\section{Geometry Installation}

Lateral distances and elevations, described above, were used to define the geometrical set up of each profile. We installed the electronically-measured geometries into ProMAX ${ }^{\mathrm{TM}}$, a seismic reflection processing software package, for each profile separately so that shot and receiver elevations and locations could be accounted for in the processing routine.

Trace Editing

Occasionally, bad coupling between the geophones and the ground, malfunctioning geophones, or cultural noise close to the seismic sensors resulted in unusually noisy traces at those locations. Traces representing those locations were edited. However, such traces were not always unsuitable for each shot gather; therefore, independent trace editing was employed for each shot gather.

\section{Timing Corrections}

Although the seisgun source electronically triggers the seismographs, there are small ( $\sim 2 \mathrm{~ms})$ delays between the electrical trigger and the actual seisgun blasts. We corrected for the delays by removing a constant 2-ms from the start time of each shot gather.

\section{Elevation Statics}

Elevation statics were applied to compensate for variations in elevations.

Electronically-determined (EDM or GPS) locations and inversion-determined velocities were used to correct the reflection times to a constant time.

Muting

To remove refractions and other arrivals that were not completely removed using filtering techniques, we used trace muting before and after stacking.

\section{Bandpass Filtering}

Most of the data of interest for this particular seismic imaging investigation are between 50 and $200 \mathrm{~Hz}$, and most of the undesirable seismic data, such as surface 
waves and cultural noise, were below about $30 \mathrm{~Hz}$. We used a bandpass filter, with a low cut of $30 \mathrm{~Hz}$, to remove most unwanted arrivals.

\section{F-K Filtering}

Not all surface waves were removed by simple bandpass filtering. To remove surface and airwaves that were not removed by bandpass filtering, we used an FK filter, which filters on the basis of velocity and frequency.

Velocity Analysis

Velocities in the shallow section $(\sim 1 \mathrm{~m}$ to $\sim 100 \mathrm{~m})$ were determined using velocity inversion techniques, but velocities in the deeper section were

determined using shot gathers, semblence, and apriori data.

Velocity Inversion

As described above, velocities were measured from the seismic data using a computerized inversion routine.

\section{Normal Moveout Correction}

Due to progressively greater traveltimes for the seismic waves to reach sensors that were progressively farther from each shot point, there was a delay (moveout) for each seismic arrival on the seismic record. To sum (stack) the data at each common depth point (CDP), a correction was made for the moveout using velocities obtained from the velocity analysis.

\section{Stacking}

To enhance the seismic signal for each common depth point (CDP), individual reflections were summed together in a process called stacking.

Depth Conversion

For stacked seismic reflection images that were not migrated, we converted the time sections to depth sections using RMS velocities converted from the velocity analysis described above.

\section{Migration}

Due to the presence of faults and diffraction points in the subsurface, diffraction hyperbolae were observed throughout the sections. We used pre-stack migration, a mathematical process that moves seismic energy (such as diffractions) back to their correct position in the subsurface, to collapse the diffraction hyperbolae.

\section{Seismic Images}

Seismic velocity images and reflection images were developed for the upper $\sim 100 \mathrm{~m}$ of each of the three profiles (Fig. 19). Both types of seismic images show velocities and reflective characteristics that are consistent with the known geology (Cox and Hillhouse, 2000). Seismic velocities also vary in a manner expected for the known geology. In addition to the fully processed and migrated images, we present unmigrated seismic images so that the diffractive nature of the subsurface can be observed. Vertical alignment of diffractive sources over large depth ranges is normally attributable to faulting.

\section{Seismic Refraction Images}

Seismic velocities were measured along each of the three intersecting profiles (Figs. 19a-d). Shot and geophone spacing of $2 \mathrm{~m}$ allowed for a maximum resolution of about 2-m. However, to make the velocity measurements more smoothly varying for 
seismic reflection stacking, we smoothed or averaged the velocity measurements over 3$\mathrm{m}$ horizontal and vertical intervals. As a result of smoothing, individual layers that are less than $3 \mathrm{~m}$ to $5 \mathrm{~m}$ thick will be represented by average velocities of layers above and below the layer in question. In particular, thin layers such as a perched water table that is less than 3 to $5 \mathrm{~m}$ thick, may not be observed with velocities expected of saturated sediments (Schon, 1996). Thus, although some studies in southern California (Catchings et al., 1998; 1999; Gandhok et al., 1999) have shown that the $1500 \mathrm{~m} / \mathrm{s}$ velocity contour corresponds to the water table in saturated sediments, such a correspondence should not be expected for the thin aquifer in the Upper Unit at GAFB.

Compressional-wave velocities range from about $500 \mathrm{~m} / \mathrm{s}$ at the surface to 2800 $\mathrm{m} / \mathrm{s}$ at depths in excess of $100 \mathrm{~m}$ (Fig. 19a-d). There are also significant lateral variations in velocity across the profiles. For example, velocities range from about 400 $\mathrm{m} / \mathrm{s}$ to $700 \mathrm{~m} / \mathrm{s}$ laterally in the upper $10 \mathrm{~m}$. However, there is much less lateral variation in the velocity at depths in excess of $25 \mathrm{~m}$. The shallow velocity variations likely result from lithological differences and from variations in water content in the upper $10 \mathrm{~m}$. For example, we noted significant lateral changes in the shallow stratigraphy, varying from sandy soils to hard clays, in the upper $0.3 \mathrm{~m}$ of the shot holes. Such depositional changes likely extend to several meters to tens of meters depth. Although the variation is less, velocities at deeper depths also vary laterally. The depth to the higher velocities $(>1500$ $\mathrm{m} / \mathrm{s}$ ) varies by 10 to $20 \mathrm{~m}$ laterally, suggesting that equivalent layers vary in depth across the profiles. The higher velocity layers along profiles GAFB 2 (Fig.19b) and GAFB 3 

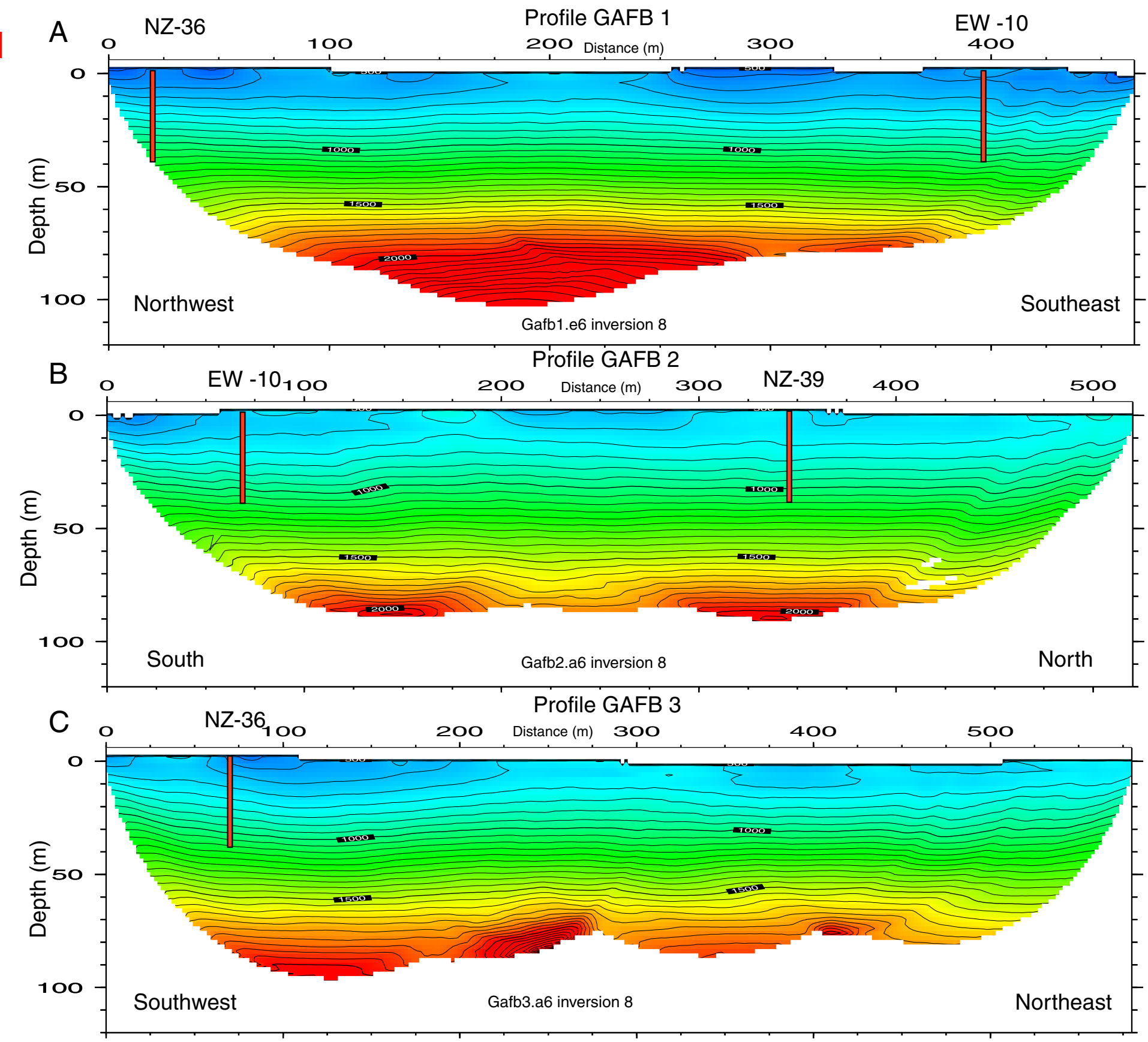

Fig. 19a,b,c Seismic velocity inversion models along profiles GAFB 1, GAFB 2, and GAFB 3. Velocity is in $\mathrm{m} / \mathrm{s}$. Depth is relative to the topographically lowest shot point along each profile. The vertical red lines mark the position of monitoring or extraction wells. 

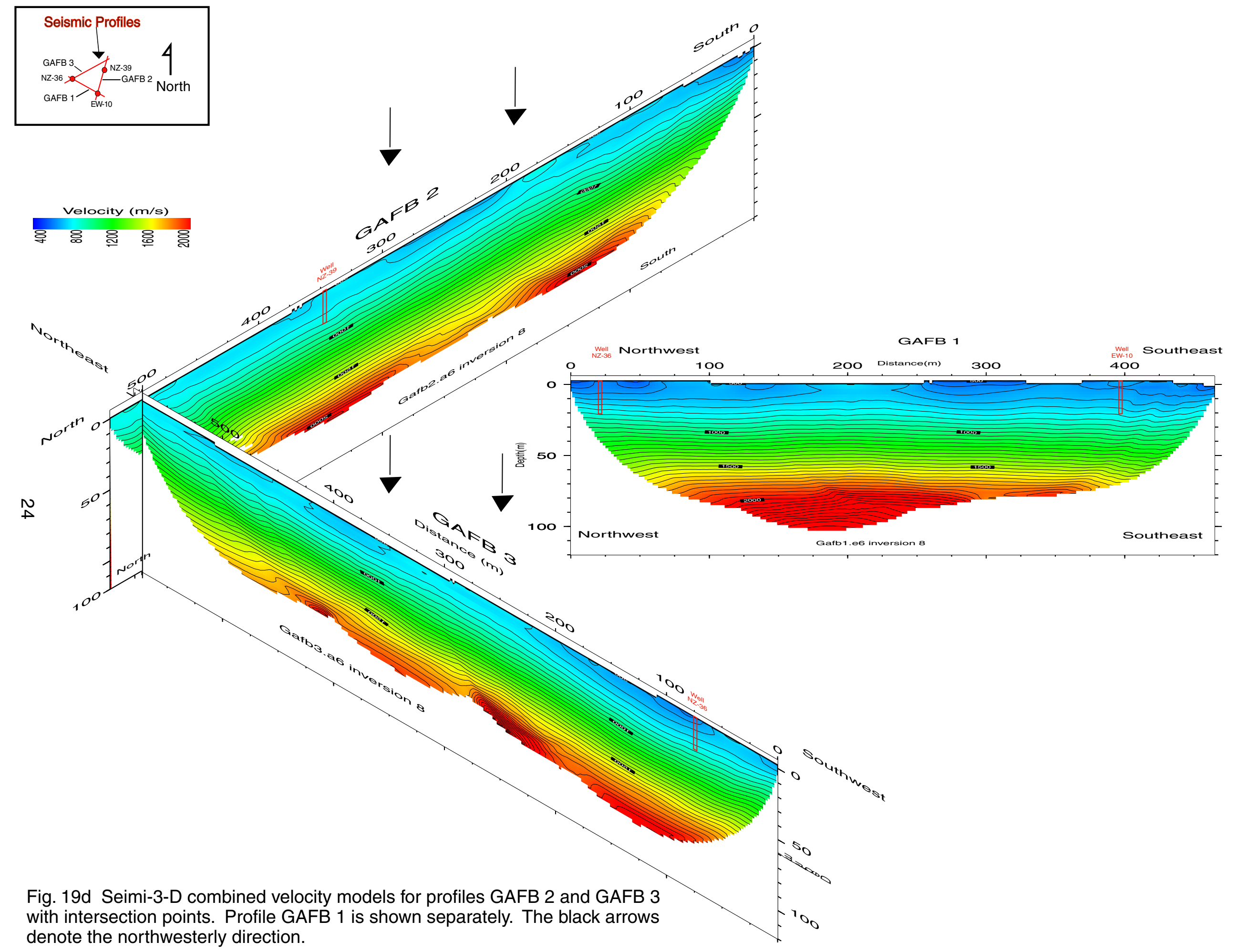


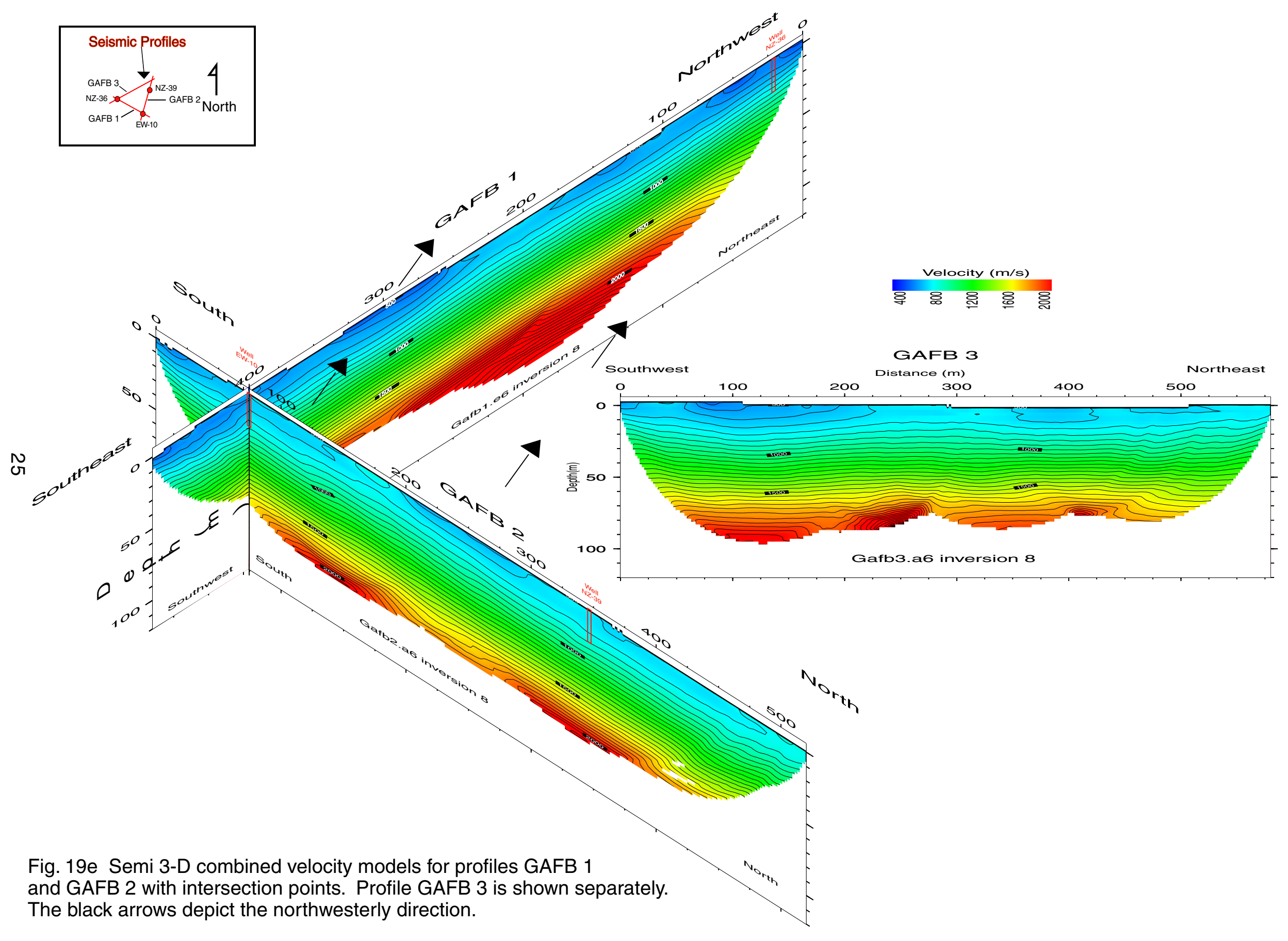



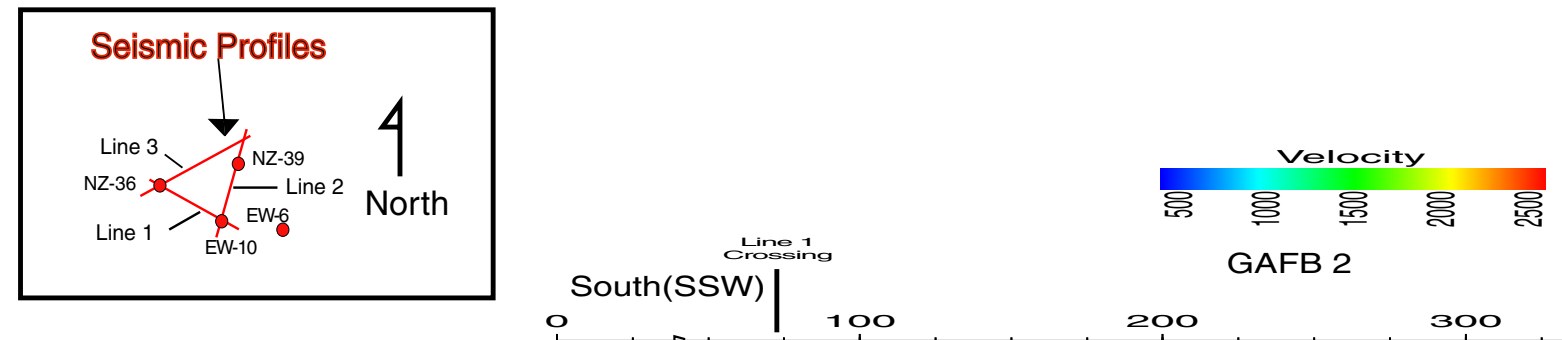

${ }_{0}^{\text {South }(S S W)} \mid 100$

GAFB 2

(tines

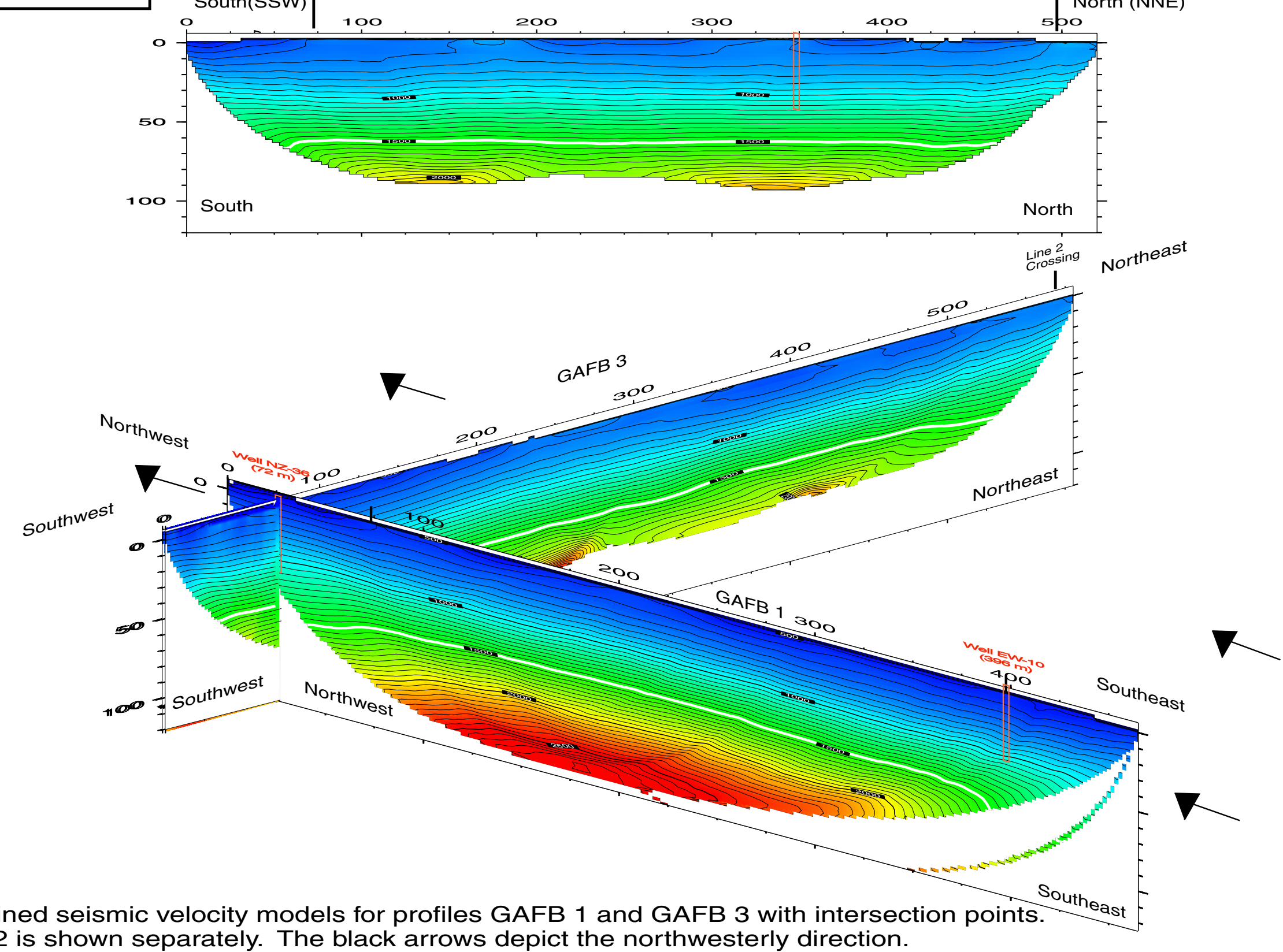

กั

Fig. $19 f$ Combined seismic velocity models for profiles GAFB 1 and GAFB 3 with intersection points. Southeast Profile GAFB 2 is shown separately. The black arrows depict the northwesterly direction. 
(Fig.19c) appear to be disturbed near the center of the profiles, suggesting that the disturbance may be trending northwestward through the two profiles.

\section{Seismic Reflection Images}

Unmigrated (uninterpreted) seismic reflection images and migrated (uninterpreted and interpreted) seismic reflection images are presented in this report to highlight important features of the shallow subsurface at GAFB. In general, the unmigrated seismic images are best at showing strong diffractive energy, and the migrated seismic images are best at showing the true structure.

\section{Profile GAFB 1}

\section{Unmigrated Data GAFB 1}

Unmigrated seismic reflection images for profile GAFB 1 is presented in figure 20. These data have been bandpass filtered to accommodate frequencies between 50 and $1200 \mathrm{~Hz}$. The lithologic logs from boreholes (NZ-36 and EW-10) located along the seismic profiles are superimposed on the data. Diffractive energy is abundant on all profiles, and it originates at all depths, suggesting that the cause of the diffractions extends throughout the seismic section. Usually such a diffractive pattern can be attributed to faults, which have offset individual layers over large depth ranges. Where the edges of the layers have been displaced due to faulting, these edges act as energy sources or diffractions. Although there are numerous and strong reflections present on the image, the reflections are poorly resolved because of the intense diffractive energy. The clearest reflections occur at depths in excess of $25 \mathrm{~m}$, and these layers appear to vary in depth in a lateral sense. To obtain a clearer view of the layers, it is necessary to migrate the data.

\section{Migrated Data GAFB 1}

We performed migration on the seismic data shown in figure 21 so that more detailed structure could be imaged. The diffractions that are so prevalent on the unmigrated image (Fig. 20) have been collapsed in figure 21, yielding a clearer image of the structure and stratigraphic layers. Both the migrated (Fig. 21) and unmigrated (Fig. 20) images show that the upper $30 \mathrm{~m}$ is highly reflective. However, due to the greater clarity of the migrated image, the laterally discontinuous nature of many of the reflections is more apparent in the migrated image (Fig. 21). Although they are not laterally continuous across the entire profile, many of these layers can be correlated with stratigraphic horizons described in lithologic logs. However, only those layers thick enough (4 to $8 \mathrm{~m}$ ) to generate a reflection at the frequencies used would be seen on the seismic image. Individual layers in the seismic image appear to vary in thickness along the section, probably owing to its fluvial deposition pattern (Cox and Hillhouse, 2000).

The upper $\sim 40 \mathrm{~m}$ apparently corresponds to the Upper Unit (see Fig. 3) described by Cox and Hillhouse (2000). The seismic image suggests that many layers in the Upper Unit are laterally discontinuous, but several layers can be traced across the length of the profile. Two of the most prominent reflections on the image occur near the base of the Upper Unit, between about 30 and $40 \mathrm{~m}$ depth. Along the length of profile GAFB 1, 
these strong reflections vary in depth by as much as $10 \mathrm{~m}$ but generally occur at shallower depths to the southeast, beyond about meter 200 (Fig.21). Most of the changes in depth are abrupt and occur within a few meters lateral distance. These abrupt changes in depth are apparently fault related, as layers above and below the strong reflections appear to be similarly offset in an abrupt manner. The upper of the two strong reflections correlates with the shallow-depth aquifer observed in Wells NZ-36 and EW- 


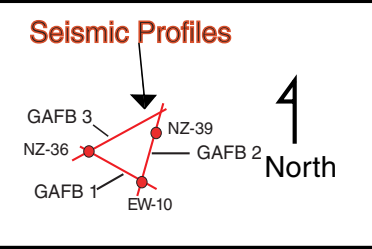

NW

응 200
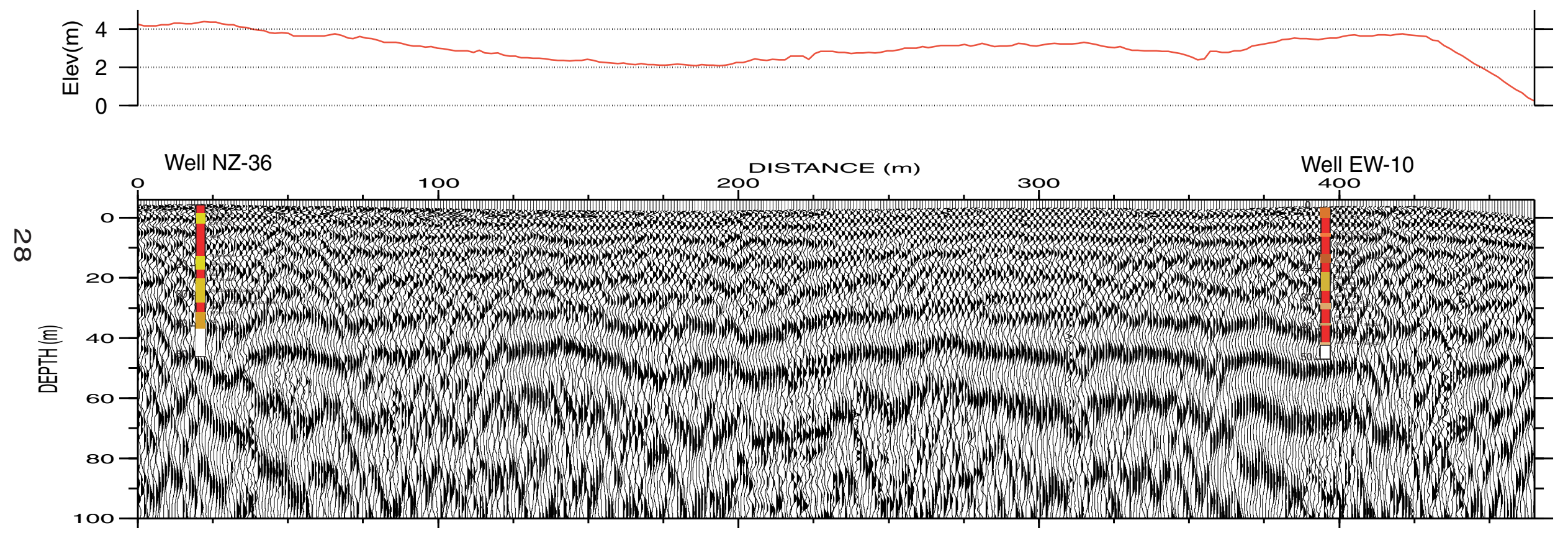

Fig. 20 Unmigrated seismic reflection image of the upper $100 \mathrm{~m}$ along profile GAFB 1. The location of wells NZ-36 and EW-10 are shown with lithologic logs. Note the numerous diffractions along the profile that extend from the near surface to the bottom of the section

Processing Parameters line $1 \mathrm{r} 2 \mathrm{f} 3$ a1 $\mathrm{v} 32$ near75: $\mathrm{agc}=500$, $\mathrm{fk}=90-400,1-200,50 \%, \mathrm{bp}=25-50-600-1200$ poststack: $\mathrm{bp}=25-50-600-1200, \mathrm{agc}=25$ 


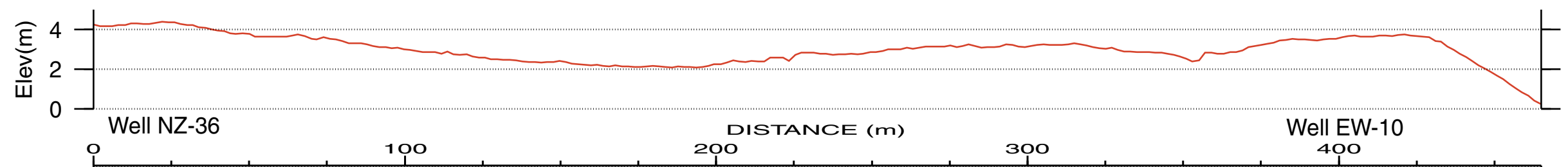

N

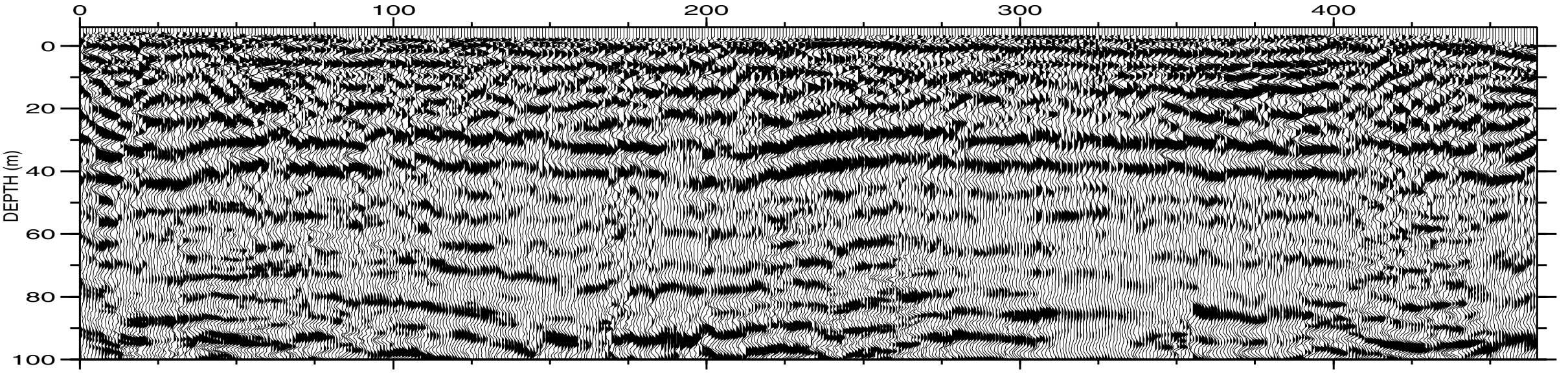

Processing Parameters

line $1 \mathrm{r} 2 \mathrm{k} 3 \mathrm{a} 1 \mathrm{p} 3 \mathrm{v} 31: \mathrm{agc}=500, \mathrm{fk}=90-400,1-200,50 \%, \mathrm{bp}=25-50-600-1200$ $\mathrm{mig}=600,30,90$ poststack: $\mathrm{bp}=50-100-600-1200, \mathrm{agc}=20$, decon $=60-8-30 / 100$

Fig. 21a Migrated seismic reflection image along profile GAFB 1. Elevation is also shown along the profile. 


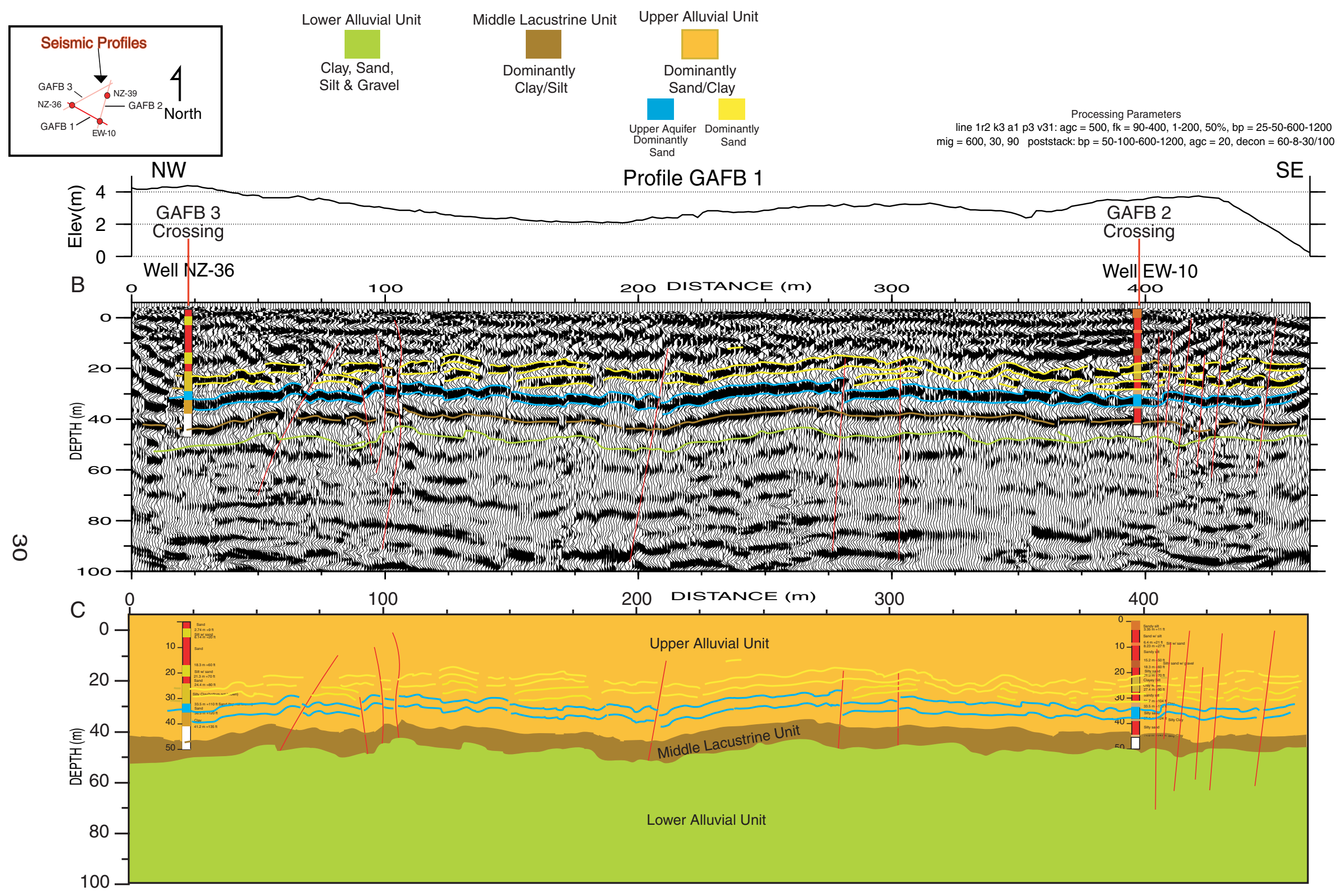

Fig. 21 (b) Migrated seismic reflection image along profile GAFB 1 with the locations of wells along the profile. The color codes on the wells are depict varying stratigraphic layers determined from well logs. Some of the prominent layers have been correlated between wells. In particular, the water-bearing sand layer (blue) is well imaged across the profile. Numerous vertical offsets in the layers are observed, suggesting abundant faulting (red lines -- not all faults drawn). (c) Interpretative geologic model along profile GAFB 1, based on the seismic image and well logs. Major geologic units from Cox and Hillhouse (2000). The thickness of Middle Lacustrine Unit is uncertain; the interpretated thickness may be over estimated, as it may only be the approximate thickness of the reflector in figure $21 \mathrm{~b}$. 
10 (see blue in Fig. 21), and the lower of the strong reflections correlates with a clay layer

(see brown in Fig. 21). The lithologic log (see Appendix 4) suggests that these layers are relatively thin $(\sim 5 \mathrm{~m})$; thus, at the frequencies used, there appears to be only one reflection event defining these layers. We interpret the reflection event outlined in brown as the top of the Middle Lacustrine Unit (see Fig. 3) described by Cox and Hillhouse (2000).

Below the two prominent reflection horizons, most reflectors are poorly defined, suggesting a markedly different physical condition. We suggest that the stratigraphic section below about $50 \mathrm{~m}$ depth corresponds to the Lower Unit (see Fig. 3) described by Cox and Hillhouse (2000), who describe the lower unit as "lacking well-defined contacts between layers" and lacking well-defined layers. Such a stratigraphic sequence would give rise to weak reflections in the seismic sections.

Apparent faults that disrupt the layers above the Lower Unit extend to the bottom of the section. Vertical offsets along the faults appear to be as much as $10 \mathrm{~m}$ in some places. Such vertical faulting is observed along most of profile GAFB 1, but there appear to greater density of faults in some areas. For example, between meters 50 to 200 and between meters 250 to 300 , faults appear to be about $15 \mathrm{~m}$ apart or less. However, the most intense faulting appears to occur beyond meter 400, where individual faults may be only a few meters apart.

\section{Profile GAFB 2}

\section{Unmigrated Data GAFB 2}

Unmigrated seismic reflection sections along profile GAFB1 are shown in figure 22. These data, like those of GAFB 1, have been had bandpass filtering applied to accommodate frequencies between 50 and $1200 \mathrm{~Hz}$. The locations of wells (Wells EW10 and NZ-39) and their lithologic logs are shown along the seismic profile. As expected, many of the same features observed on profile GAFB 1 are also observed on profile GAFB 2. In particular, diffractions also appear to be more abundant along profile GAFB 2 than along GAFB 1.

\section{Migrated Data GAFB 2}

The corresponding migrated seismic reflection section for GAFB 2 is shown in figure 23a. As observed along profile for GAFB 1, these data also show numerous reflections in the upper $40 \mathrm{~m}$, but the reflections appear stronger and more coherent along profile GAFB 2. Many of these reflections are also laterally discontinuous, probably as a result of the fluvial deposition environment. The stronger reflections in the upper $40 \mathrm{~m}$ may suggest that the layers are anisotropic, resulting from preferred deposition direction (flow direction). If that is the case, velocities may be more distinct among the layers in GAFB 2 than in GAFB 1. Alternatively, profile GAFB 2 may be oriented more normal to structural complexities (such as faults) than profile GAFB 1.

The seismic image shows similar reflectors as observed in profile GAFB 1, and there is a good correlation between individual reflections and layers identified on the lithologic logs (Fig. 23a). In particular, a strong reflector that correlates with the upper aquifer unit observed in Wells EW-10 and NZ-39 also correlates with the same strong reflector identified along profile GAFB 1 and Wells NZ-36 and EW-10 (Fig. 21a-c). 
Similarly, a reflector that apparently corresponds to top of the Middle Lacustrine Unit also correlates with that observed on profile GAFB 1. However, in several places (meters 25-75, 225-250, and 485-410) the reflector corresponding to top of the aquitard (Middle Lacustrine Unit) appears to be missing along profile GAFB 2 (Fig. 23a-c). This may have implications for the vertical flow of water and contaminants, as discussed in the conclusion section. The most abrupt change in the depth of the upper aquifer and the layers immediately above and below it occurs south of Well EW-10 near an area where the underlying aquitard may be missing along this part of profile GAFB 2 (Fig. 23a-c). 


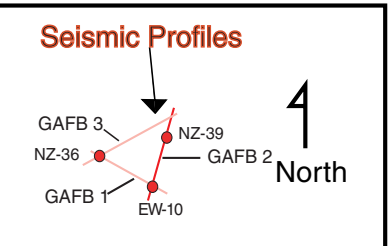

South

Profile GAFB 2

North

$\underset{0}{0} \begin{gathered}200 \\ 0\end{gathered}$

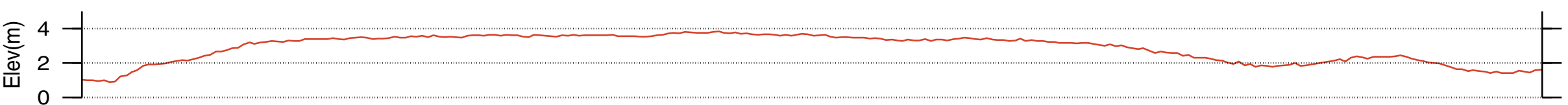

0

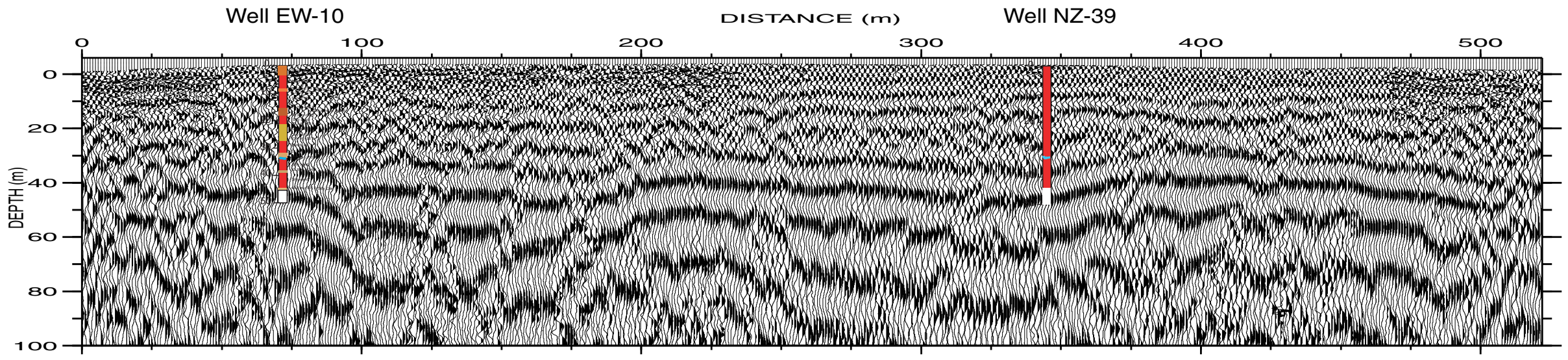

Fig. 22 Unmigrated seismic reflection image along profile GAFB 2 with locations for wells EW-10 and NZ-39. Elevation and fold along the profile is also shown. Note the numerous diffractions and offsets in reflections from the near surface to the bottom of image.

\section{Processing Parameters}

line 1r2 f3 a1 v12 near75: agc $=500$, $f k=90-400,1-200,50 \%, b p=25-50-600-1200$ poststack: $\mathrm{bp}=25-50-600-1200, \mathrm{agc}=25$ 


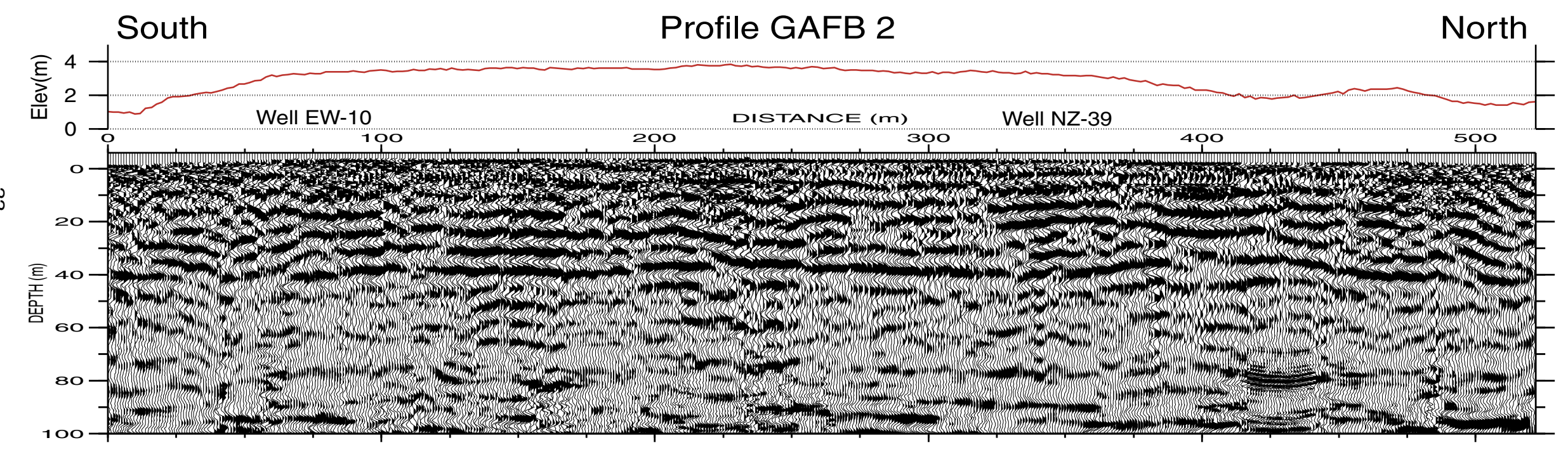

Fig. 23a Migrated seismic reflection image along profile GAFB 2. Relative elevation along the profile is also shown. 


Seismic Profiles
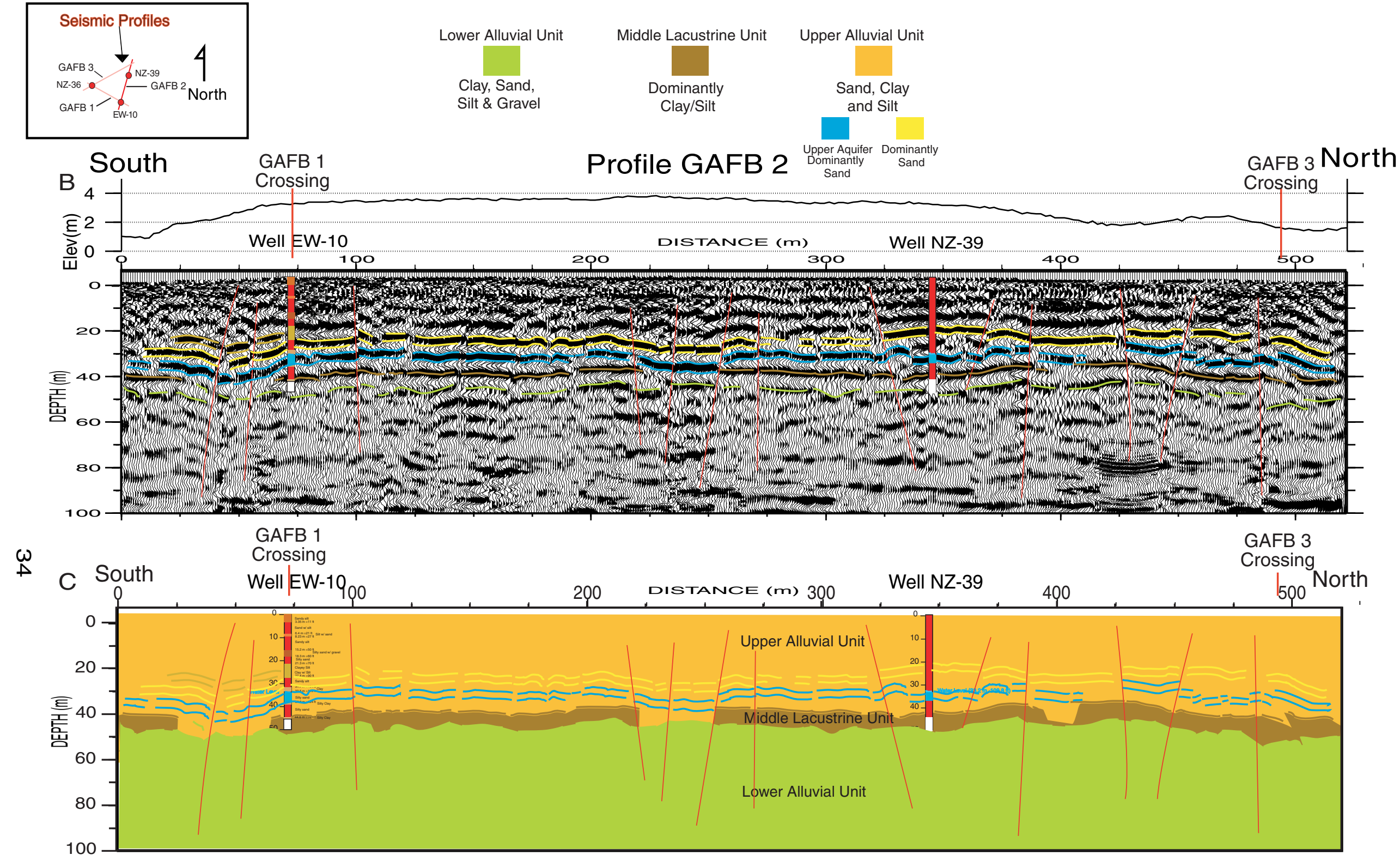

Fig. 23 (b) Interpreted seismic reflection image along profile GAFB 2. Wells, with simplified lithologic logs, are shown along the seismic profile. Major lithologic units identified in the well are highlighted with colors. Of particular importance is the reflector highlighted in blue, which corresponds to the shallow aquifer. Some of the apparent faults are also identified by near-vertical red lines. (c) Interpretative geologic model along profile GAFB 2 using the units described by Cox and Hillhouse (2000). 

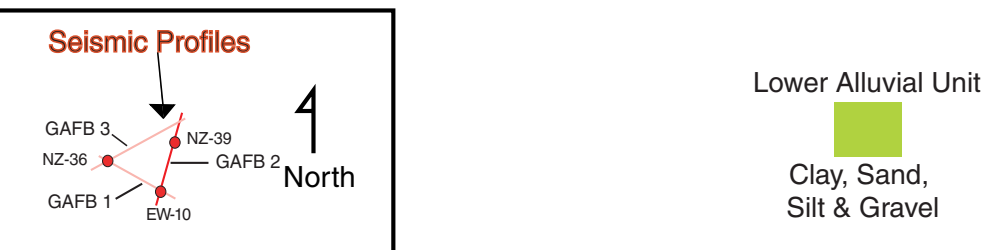

Middle Lacustrine Unit

Upper Alluvial Unit

GAFB 1

Silt \& Gravel

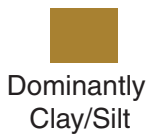

Sand, Clay
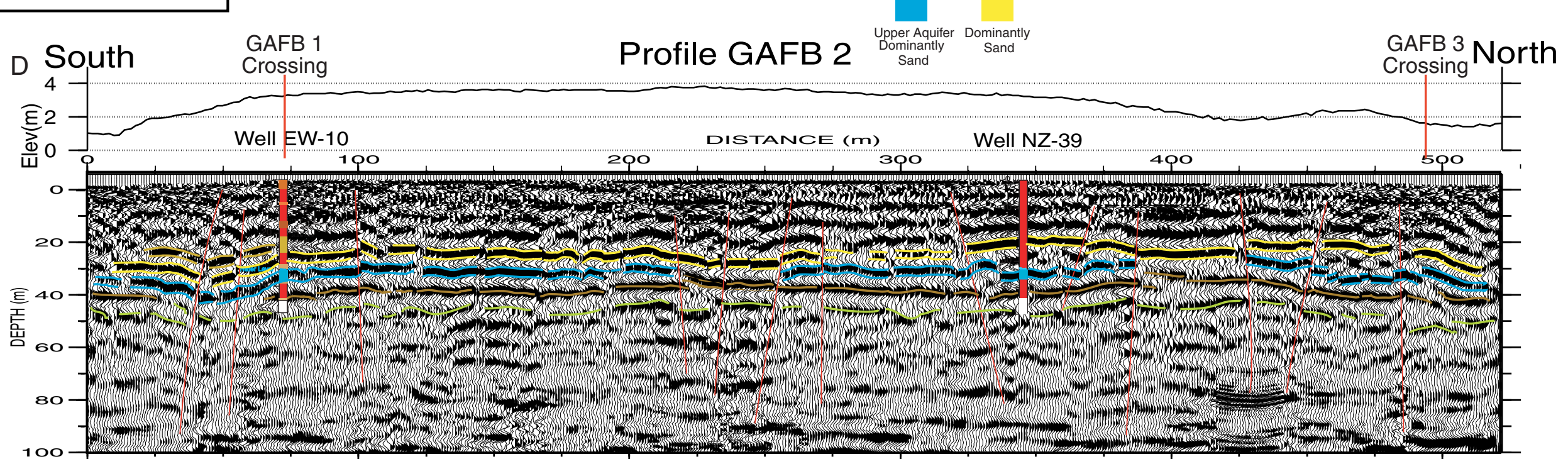

GAFB 1
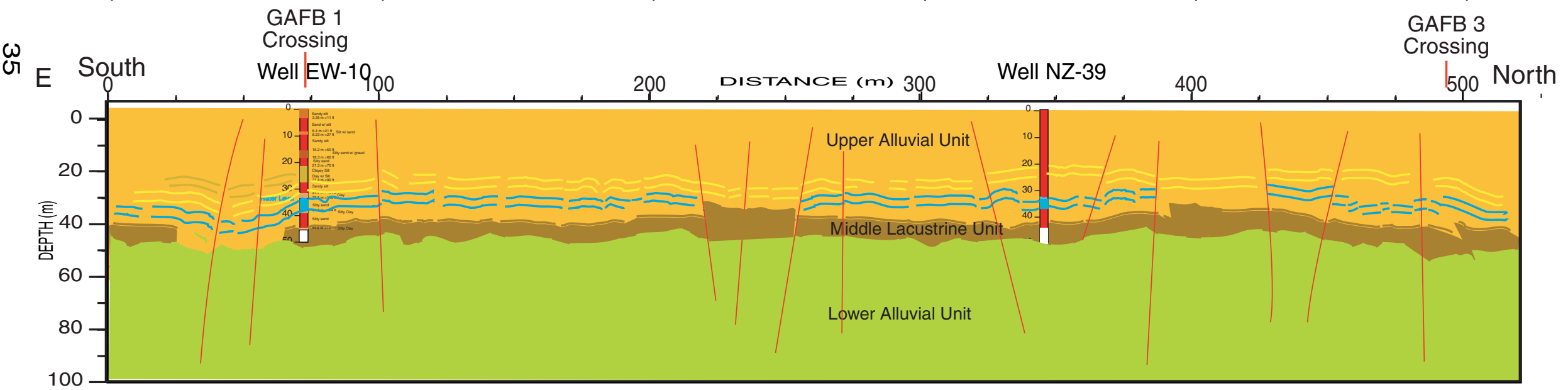

Fig. 23 (d) Alternative interpreted seismic reflection image along profile GAFB 2. This interpretation is similar to that of figure 23b, but we have used the alternative interpretation of a discontinuous water table between meters 225 and 265 and meters 485 and 425. Our preferred interpretation, however, is that of figure 23b. (e) Alternative geologic interpretation. 
The alignment of the stratigraphic section above and below the Middle Lacustrine Unit suggests that it is missing along the profile in the places listed above, however, we present an alternative interpretation, whereby the upper aquifer is missing in those areas (Fig. 23c,d). Such an alternative interpretation is less consistent with structures associated with layers above and below the Middle Unit, but we can not rule out this interpretation without additional data. The interpretation presented in figures $\mathbf{2 3 b}$ and 23c is, however, our preferred interpretation,

Reflectors below about $40 \mathrm{~m}$ depth are less well defined in profile GAFB 2 (Fig. 23) than in profile GAFB 1 (Fig. 21), probably as result of the physical condition of the lower unit (Cox and Hillhouse, 2000) and due to its orientation relative to structure. However, the weaker reflections below $40 \mathrm{~m}$ depth appear to be vertically offset in the same sense as the reflections in the upper $40 \mathrm{~m}$. This suggests that faulting that affected the lower unit occurred after or continued during the deposition of the upper unit.

Faulting along profile GAFB 2 appears to be pervasive across the entire profile, with vertical offsets on the order of $10 \mathrm{~m}$ and horizontal spacing on the order of 10 to 20 meters. However, the faults appear to be better imaged, and perhaps more abundant than those observed on profile GAFB 1. The better-imaged structure and faults may be due to the orientation of the profile relative to the strike of the faults. If, for example, the faults are oriented in a northwest direction, and profile GAFB 2 is oriented in a northeast direction, the perpendicular orientation of profile GAFB 2 to the fault planes would yield a clearer image.

\section{Profile GAFB 3}

\section{Unmigrated Profile GAFB 3}

An unmigrated seismic reflection image along profile GAFB 3, with the same filtering parameters $(50-1200 \mathrm{~Hz}$ ) as those of profiles GAFB 1 and 2, is shown in figure 24. The unmigrated image for profile GAFB 3, like those of the other two profiles, show numerous diffractions, suggesting that is pervasive faulting along the profile. One borehole (NZ-36) was located along profile GAFB 3.

\section{Migrated Profile GAFB 3}

The migrated image along profile GAFB 3 (Fig. 25a) shows a stratigraphic pattern similar to that of the other two profiles, with highly reflective stratigraphy above about $40 \mathrm{~m}$ depth, a pair of strong reflectors from about $25-40 \mathrm{~m}$ depth, and weakly reflective strata below about $40 \mathrm{~m}$ depth. There is a good correlation among GAFB 3, the other two profiles where they intersect profile GAFB 3, and the lithologic log for Well NZ-36. Of particular importance, the upper aquifer can be laterally traced across the profile; however, there are two areas where the upper aquifer appears to be missing (meters 265-325 and meters 390-480) along profile GAFB 3 (Fig. 25bc). Where the aquifer appears to be missing, the aquifer is either sufficiently thin that it does not give rise to a reflection event at the frequencies used or it is simply not present. The lack of a thick aquifer (or any aquifer at all) in some locations along the profile may be related to deposition patterns that were influenced by faulting. Thus, the aquifer may never have been deposited or it may have preferentially eroded away in selected areas with high flow rates, such as small graben or channels that were topographically lowered by fault 
movements. Near Well NZ-36, there appear to be minor structural complexities associated with the aquifer, but it is difficult to determine if the complexities result from faulting or is related to pumping (Fig. 25b).

The Middle Lacustrine Unit along profile GAFB 3 appears to be continuous across the profile, but the depth of the unit appears to vary across the profile. The image of the Lower Unit along profile GAFB 3 is also similar to its image along the other two profiles 


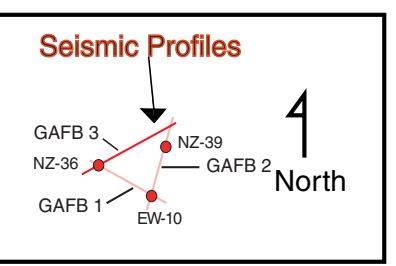

SW

은 200 크
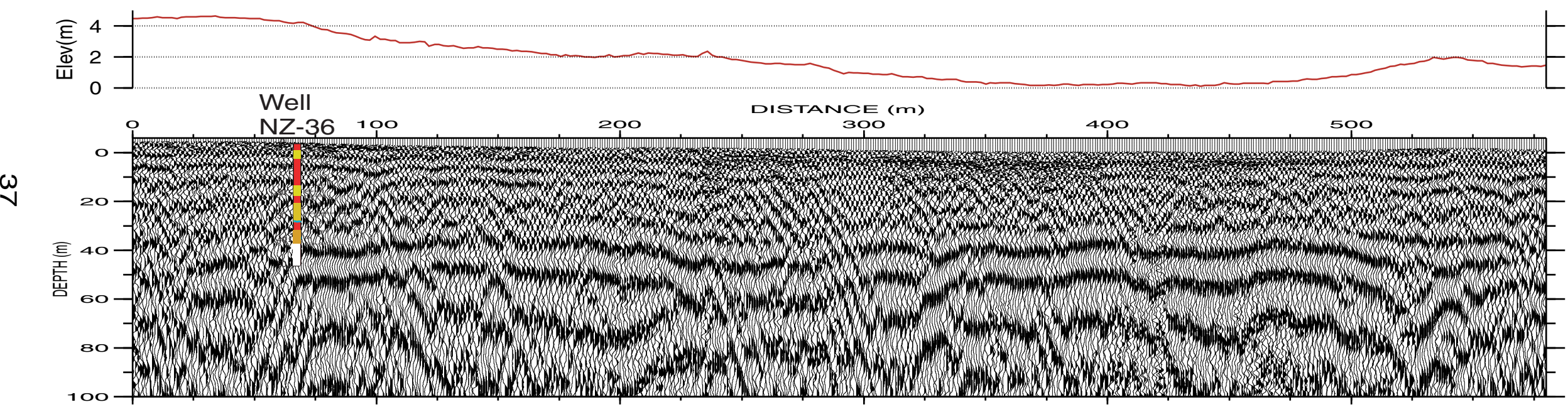

Fig. 24 Unmigrated seismic reflection image along profile GAFB 3 with the location and lithologic log for Well NZ-36. Note the large number of diffractions extending from the near surface to the bottom of the image along profile GAFB 3. 


$$
\text { Seismic Profiles }
$$

\section{GAFB - Line 3}
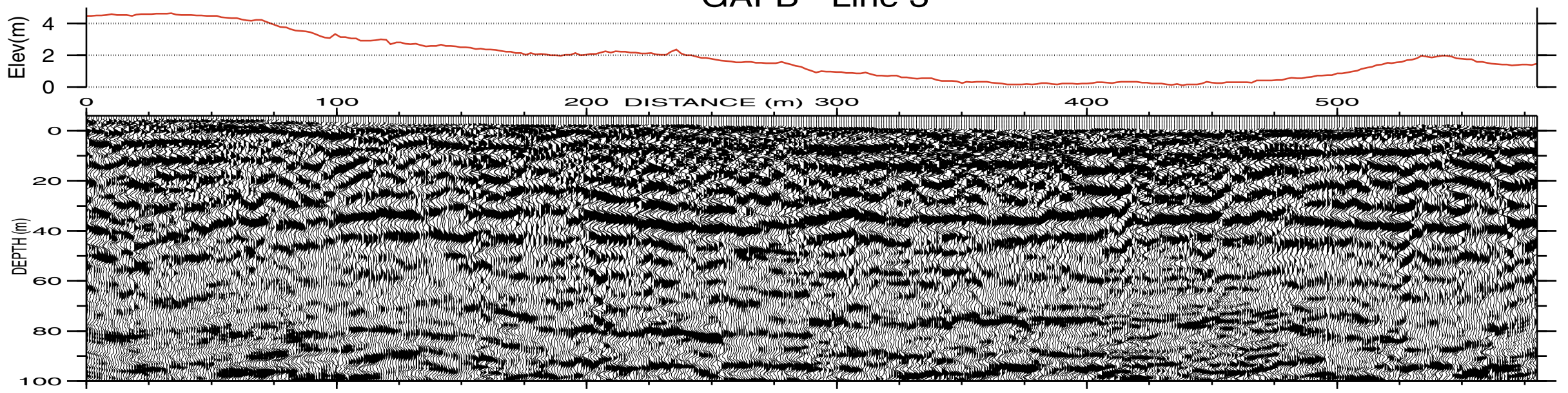

Fig. 25a Migrated Seismic reflection image along profile GAFB 3 with elevation along the profile. 


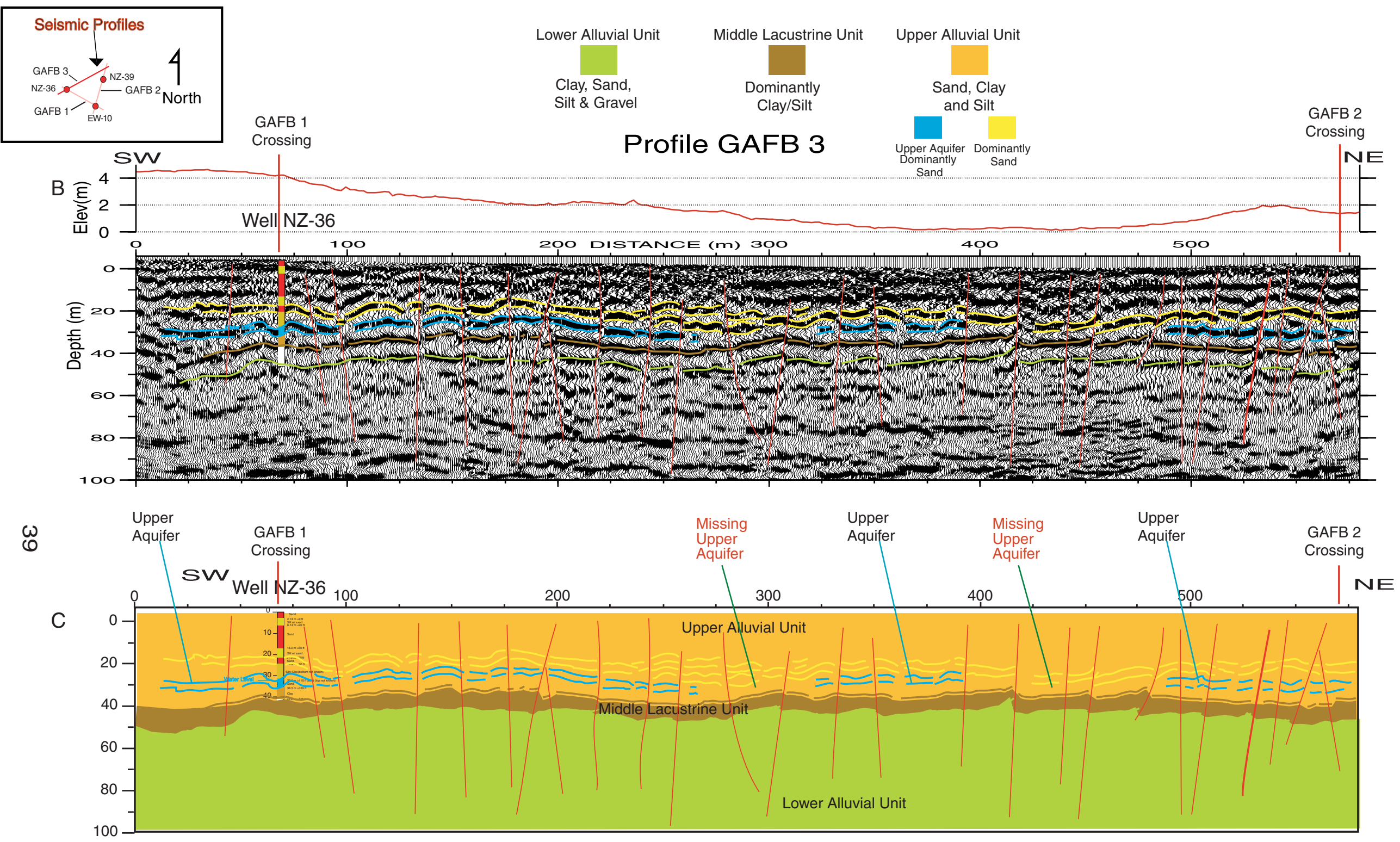

Fig. 25 (b) Interpretated, migrated seismic reflection image along profile GAFB 3 with location of Well NZ-36. Colors show lateral interpretated correlations of stratigraphy. Note that the upper aquifer (blue) is missing along two areas of the seismic profile. Numerous faults (near-vertical red lines), with minor vertical offsets, are interpreted along the section. (c) Interpretative geologic cross section along profile GAFB 3 based on stratigraphy described by Cox and Hillhouse (2000) and observed in the boreholes. 
Perhaps the greatest difference between profile GAFB 3 and the other two profiles is the apparent density of faults (Fig. 25c). Profile GAFB 3 appears to have more faults per unit area than does profile GAFB 2, and profile GAFB 2 appears to have more faults per unit area than does profile GAFB 1. Although faults in profile GAFB 1 appear to be concentrated in a few zones, those in profile GAFB 3 appear uniformly distributed across the profile. However, faults in GAFB 3 appear to have similar vertical offsets as the other two profiles.

\section{Three-Dimensional Image}

Because profiles GAFB 1, GAFB 2, and GAFB 3 intersect, the three profiles can be combined into a semi-3-D image of the study area (Fig. 26). The 3-D image infers the lateral variation of the major lithologic units between the profiles. Although some of the individual layers within the Upper and Lower Units are discontinuous across the area of the seismic survey, the most layers are continuous across the area. The Middle Unit and the upper aquifer are present along the length of profile GAFB 1, but one or both of these units are missing along parts of profiles GAFB 2 and GAFB 3. The continuous nature of these units along profile GAFB 1 suggests that they may be continuous in a northwesterly direction, but these units are apparently broken in a northerly or northeasterly direction. This suggests that structures in this area may be segmented into northwest-trending blocks. Along profile GAFB 3, the aquifer is clearly segmented, but the direction of the segmentation can only be inferred. However, if the aquifer is segmented into northwesttrending blocks, ground-water flow and, therefore, contaminant transport may be affected. If the Middle Unit is missing in places along the profile, vertical flow of groundwater and contaminants may have occurred.

\section{Discussion}

The seismic profiles suggest a stratigraphic column in the GAFB area that is very much like that described by Cox and Hillhouse (2000). In general, the upper $40 \mathrm{~m}$ (Upper Fluvial Unit) are characterized by highly reflective layering, whereby some of the layers are continuous across the area and others are discontinuous. Such a seismic signature is expected of sediments deposited in a fluvial environment, where some layers extend for great distances and others are limited in their geographical extent. Correlation of reflections on the seismic image with lithologic logs from wells situated along the seismic profiles shows that the reflections arise from a series of sand, clay, and silt layers in the Upper Fluvial Unit. Perhaps the most important of these layers (for purposes of this study) are those comprising the aquifer system (aquifer and aquitard). Based on correlations with the lithologic logs, the aquifer system is well imaged across each of the profiles, and the seismic images suggest that the aquifer system is considerably complex, probably owing to its depositional and tectonic history. Over the entire study area, it is unclear which layers are a part of the aquifer system, but the seismic images suggest that the Middle Lacustrine Unit may be directly associated with the aquifer system in places.

The Middle Lacustrine Unit is primarily composed of clay and other fine-grained sediments. On the seismic images, this unit or at least its top, appears as a strong reflector directly beneath the upper aquifer in most places. In some places, however, the Middle Lacustrine Unit appears to have been eroded in structural depressions that appear 
to be fault bounded. If this unit represents the aquitard to the upper aquifer, and it is not present in places, there may be vertical flow of ground water associated with those areas where the unit is not present. On the basis of the seismic images, the Middle Lacustrine Unit appears to be less than about $10 \mathrm{~m}$ thick, but because only one reflection is observed, it may be much less than $10 \mathrm{~m}$ thick. The depth to the base of the Middle Unit and to the top of the Lower Unit is not resolved by the seismic images. However, the 


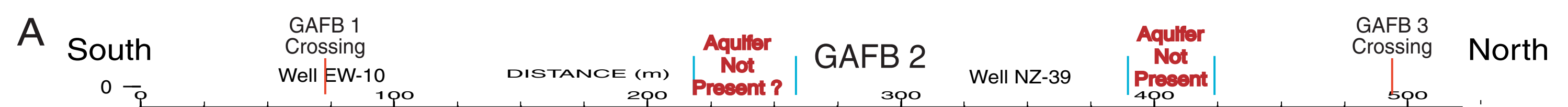

40

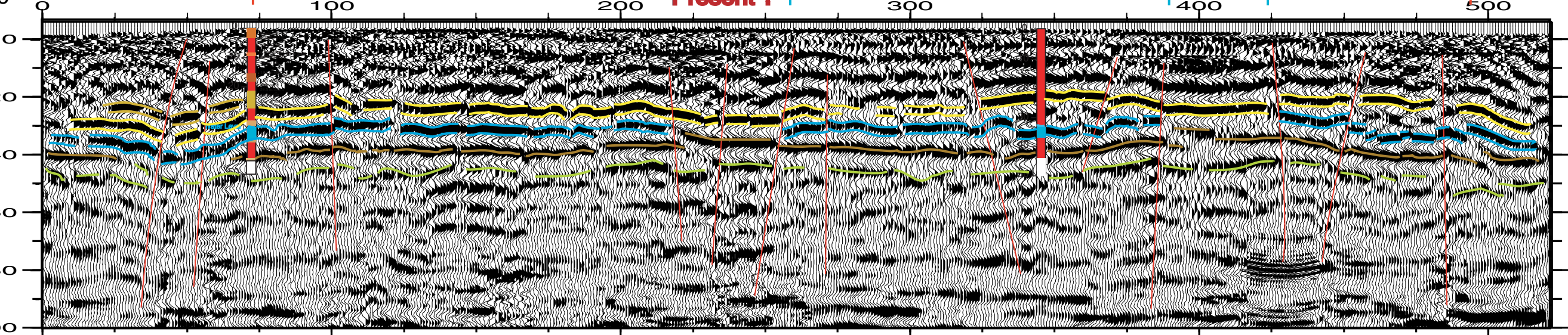

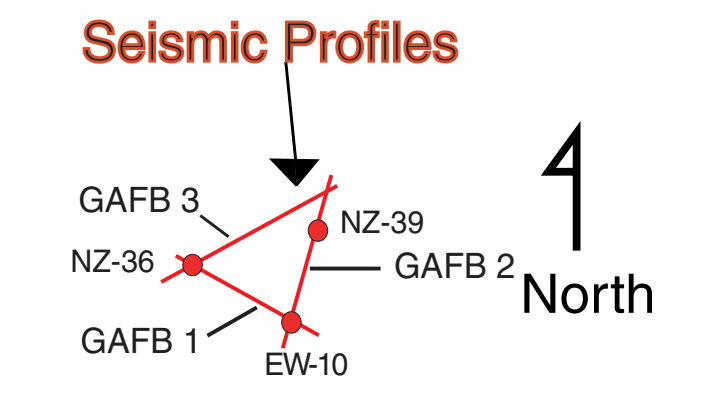

$\stackrel{\Delta}{\Delta}$

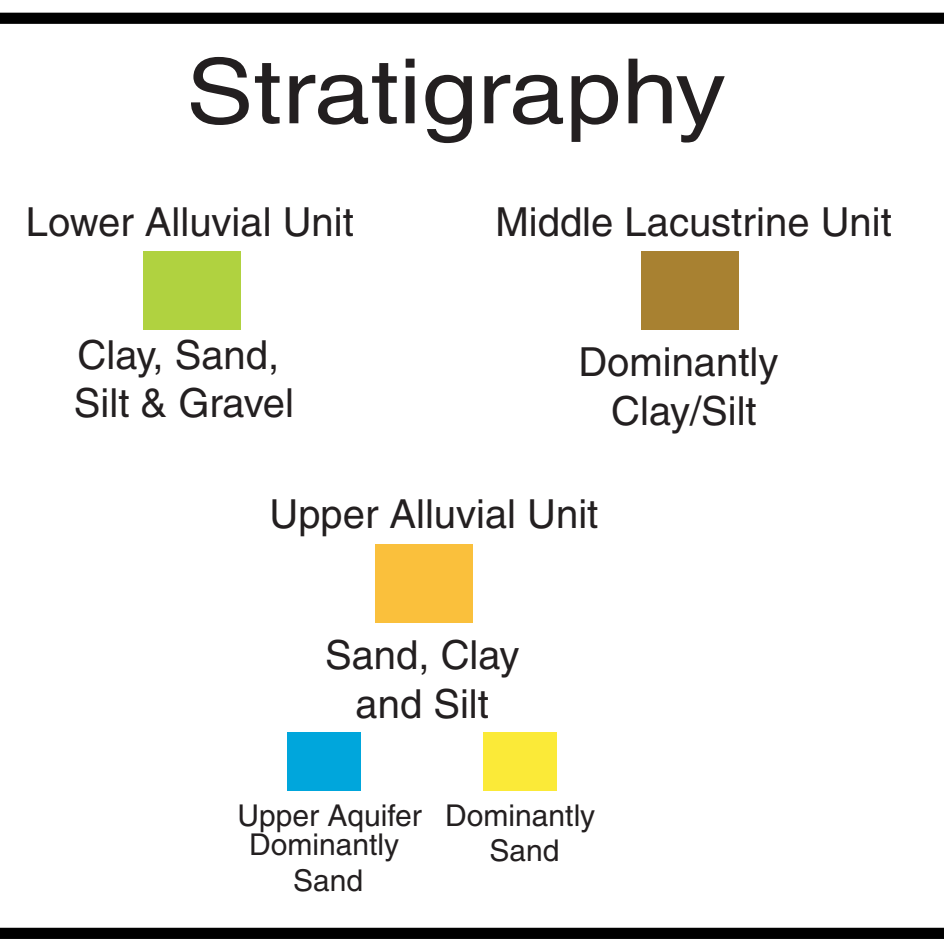

Fig. 26 (a) Seismic reflection image along profile GAFB 2 with alternative interpretation from figure 23d, showing a missing upper aquifer. (b) Semi-3-D seismic reflection image along profiles GAFB 1 and GAFB 3. Note the continuous upper aquifer along profile GAFB 1 and the discontinuous upper aquifer along profile GAFB 3. Southeastward projection of the missing aquifer would place it along profile GAFB 2 as shown in part a.

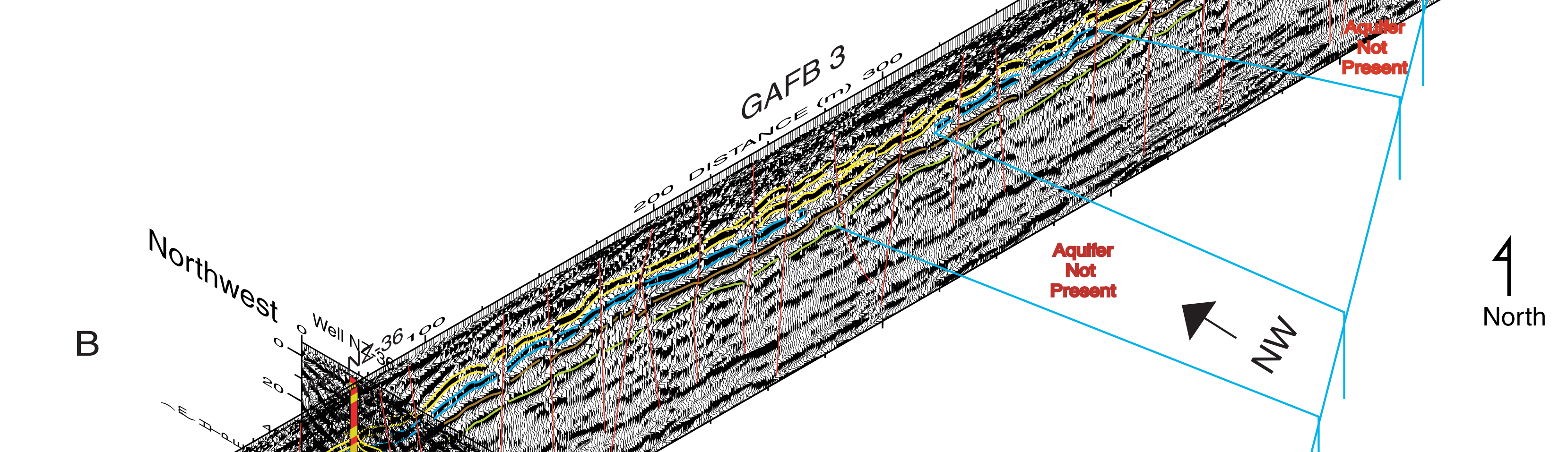


stratigraphy below the Middle Lacustrine Unit is markedly different that the rest of the seismic image. Below the Middle Lacustrine Unit, individual layers are not well defined.

Cox and Hillhouse (2000) suggest that these layers have been deeply eroded and that the contacts between the layers are not easily distinguished. On the basis of their description, the reflections directly below the Middle Lacustrine reflection probably arise from the Lower Alluvial Unit. From that depth to about $100 \mathrm{~m}$ below ground surface, the seismic image shows varying reflectors of the Lower Alluvial Unit.

The seismic profiles show that faults are pervasive throughout the study area. The imaged faults offset all layers. These data further suggest that there is a northwesterly trend to the faults. This northwesterly trend of the faults probably affects the lateral flow of ground water, as faults are usually barriers to flow of ground water in sedimentary basins. If the faults act as barriers to flow, it is likely that there is a northwest-southeast component of ground water flow, as ground water would flow parallel to the trend of the faults. This flow direction may be inferred from the continuity of the aquifer relative to the three profiles. The upper aquifer is continuous across profile GAFB 1, but it is discontinuous in places across profiles GAFB 2 and GAFB 3, with the greatest discontinuity along profile GAFB 3. This may suggest that the aquifer is channeled along northwest-southeast-oriented lines because profile GAFB 1 is probably more parallel to structure (faults, deposition directions), and profiles GAFB 2 and GAFB 3 are more perpendicular to structure.

The proposed northwest-southeast orientation of faults and other structures in the OU-1 area may be indicated by the contaminant flow pattern. The highest concentrations of contaminant are apparently oriented in a northwest-southeast direction, nearly perpendicular to profile GAFB 3 (Fig. 27). Although these contours are drawn as highly concentrated circular areas, we suggest that such circular contours are not required by the placement of the available wells. The contaminant concentration pattern in the western part of the OU-1 area and the "approximate edge of the upper aquifer" also show northwesterly trends (Fig. 27). Another indication of the northwest-southeast orientation of faults and other structures is the available evidence for faulting in the area and in the region. From a regional perspective, it is clear that the major mapped faults in the area have a predominant northwesterly trend (see Fig. 28). On a more local scale, geologic mapping by Cox (in Catchings et al., 2000) shows a predominant northwesterly orientation of lineaments (faults) southeast of GAFB (Fig. 29). These lineaments trend directly to the northwest toward GAFB, and many of them were confirmed as faults in high-resolution seismic images (Catchings et al., 2000). On a scale confined to GAFB, Cox (pers. comm., 2000) inferred northwest-trending faults near the southwest corner of GAFB on the basis of stratigraphic differences observed from boreholes. Locally, near the OU-1 area, Cox (pers. comm. , 2000) also inferred a northeasterly set of lineaments, but they have not been confirmed as faults (Fig. 2). However the parallel flow lines, in a rough sense, do follow Cox's inferred faults south of OU-1. Within OU-1, the parallel flow lines are oriented northwesterly.

\section{Conclusions and Suggestions}

TCE contaminant mitigation efforts at GAFB would probably progress most readily if the subsurface structure were known, particularly that of the upper aquifer, which is presumed to transport the TCE. In the OU-1 area, seismic data from this study 
show that the upper aquifer can be laterally mapped between wells and that accurate depths to the aquifer can be determined. The aquifer appears to be laterally discontinuous when viewed along north-northeasterly oriented profiles, but the aquifer appears to be continuous when viewed along northwesterly oriented profiles. In all profiles, the aquifer appears to be vertically displaced by numerous faults, with vertical displacement of $10 \mathrm{~m}$ or more. Such large variations in the depth of the aquifer would certainly make it difficult to drill monitoring or extraction wells to the proper depth. If such wells were drilled to depths that are too shallow, those wells would not intersect the aquifer, and if they were drilled too deeply, there is the risk of puncturing the aquitard. If the aquitard were punctured, there is the risk of allowing contaminants to migrate to greater depths, down to the regional aquifer.

The faults that have apparently displaced the aquifer appear to have a predominant northwesterly trend, which may encourage northwesterly flow of ground water and contaminants. Usually, faults in sedimentary basins act as barriers to flow; therefore, a predominant northwest orientation of faults might encourage northwest flow along the faults. One example of northwest-oriented faulting that may have encouraged northwest-southeast-oriented ground-water flow is the Mojave River. Most water associated with the Mojave River occurs as ground water (Catchings et al., 2000), and the Mojave River clearly has a northwesterly flow direction. Based on detailed mapping in the area, Cox (pers. comm , 2000) suggests that the Mojave River follows a shear zone that is characterized by intense faulting, and based on seismic images in Victorville and at GAFB, this zone of intense faulting appears to extend into the OU-1 area. Smaller scale ground-water flow in the OU-1 area may follow a similar pattern to the Mojave River.

TCE concentration maps the orientation of the edge of the upper aquifer, parallel flow lines (Fig. 27), known regional faults (Fig. 28), and known local faults (Fig. 29) all have a predominant northwesterly orientation. This suggests that there may be a northwesterly component of ground-water flow (and therefore, TCE) in the GAFB area.

If there is a northwest-southeast component ground-water flow, some future monitoring wells should be drilled to the north and west or south and east of existing TCE "hot spots." In some locations, the relatively thick clay layer that underlies the aquifer may be missing or very thin (see Fig. 25). Without that barrier, it may be possible for ground water (and contaminants) from the upper aquifer to penetrate to greater depths. In areas without the clay aquitard, deeper monitoring wells should be considered to evaluate whether contaminants have migrated to greater depths.

\section{Acknowledgments}

We thank James Chang, Stephen Niou, and Harold Reid for providing valuable data and guidance in conducting this study. We thank Joe Catchings, Jeff Dingler, Andy Gallardo, Samantha Hansen, Keith Rice, Mike Taylor, Deborah H. Underwood and Chizuru Suzuki for field assistance and Allan Christensen for GPS surveying. Thanks to Lora Kiger for careful review of the manuscript. 


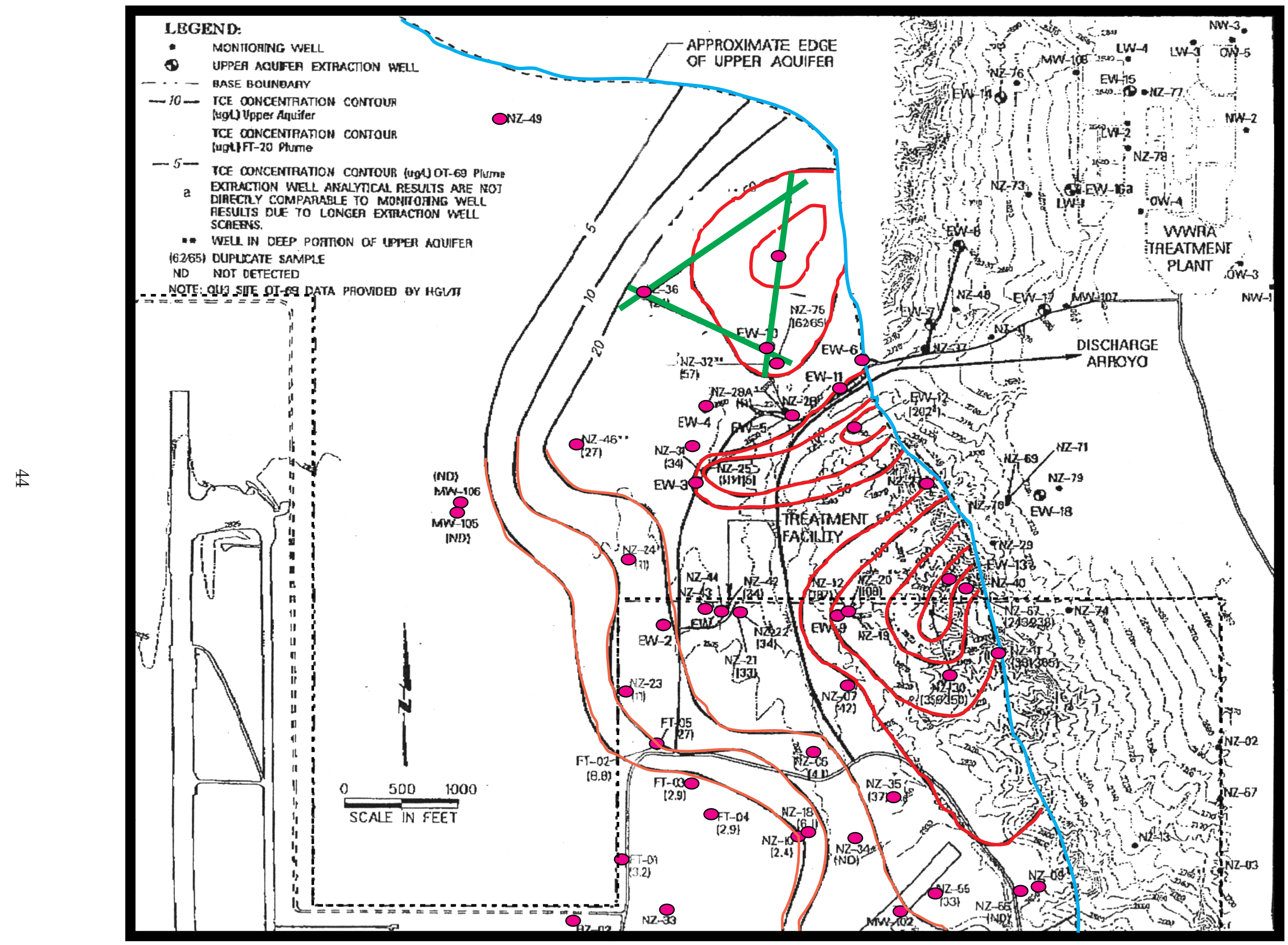

Fig. 27 TCE concentration map from Montgomery-Watson (1995). Note the northwest trend of the high TCE concentrations (red contours) and the edge of the upper aquifer (blue line). The seismic profiles from this study are shown in green. 


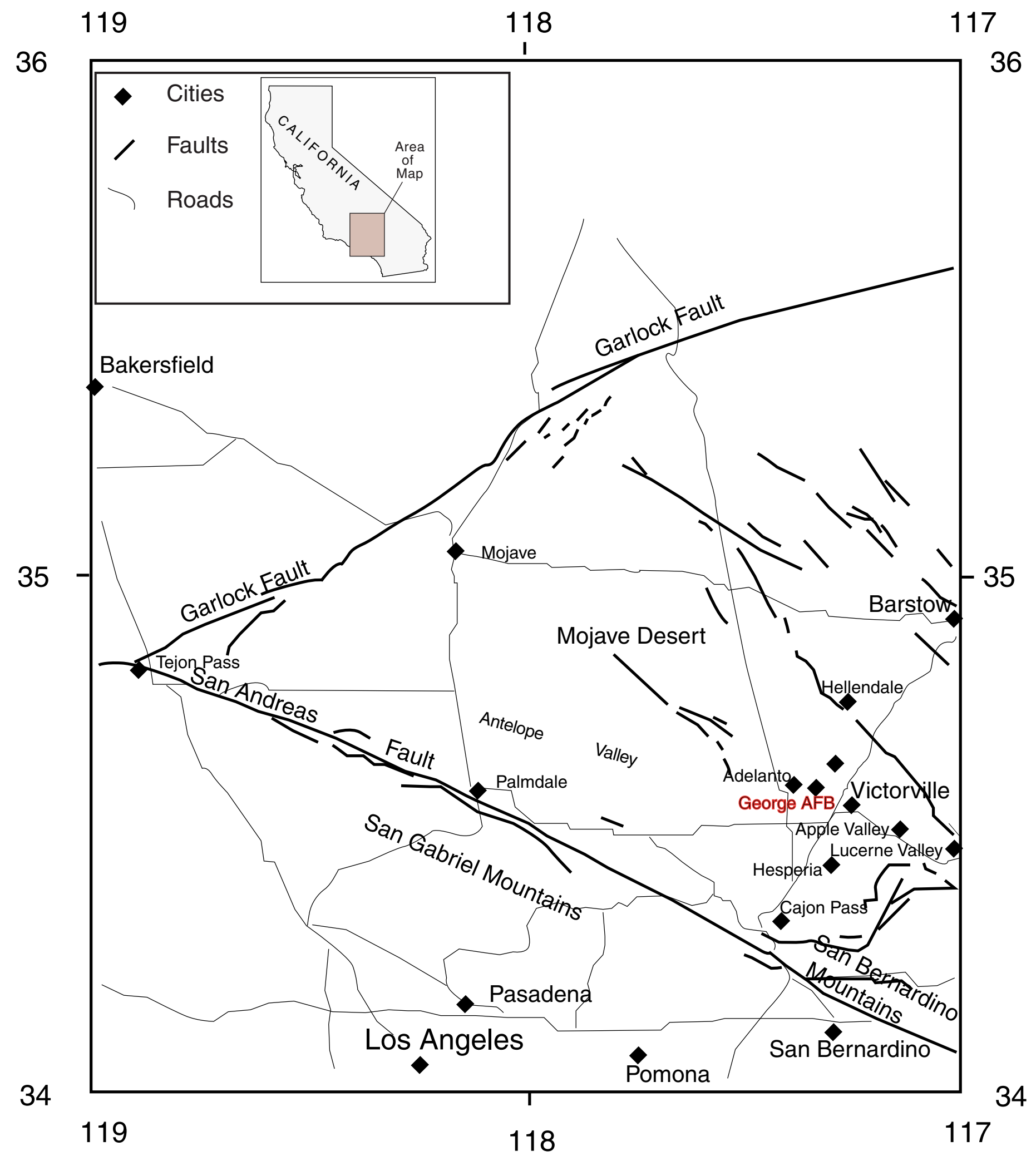

Fig. 28 Major mapped faults of the area around George Air Force Base. Note the northwestward orientation of most faults in the area. 
3.5 km To GAFB

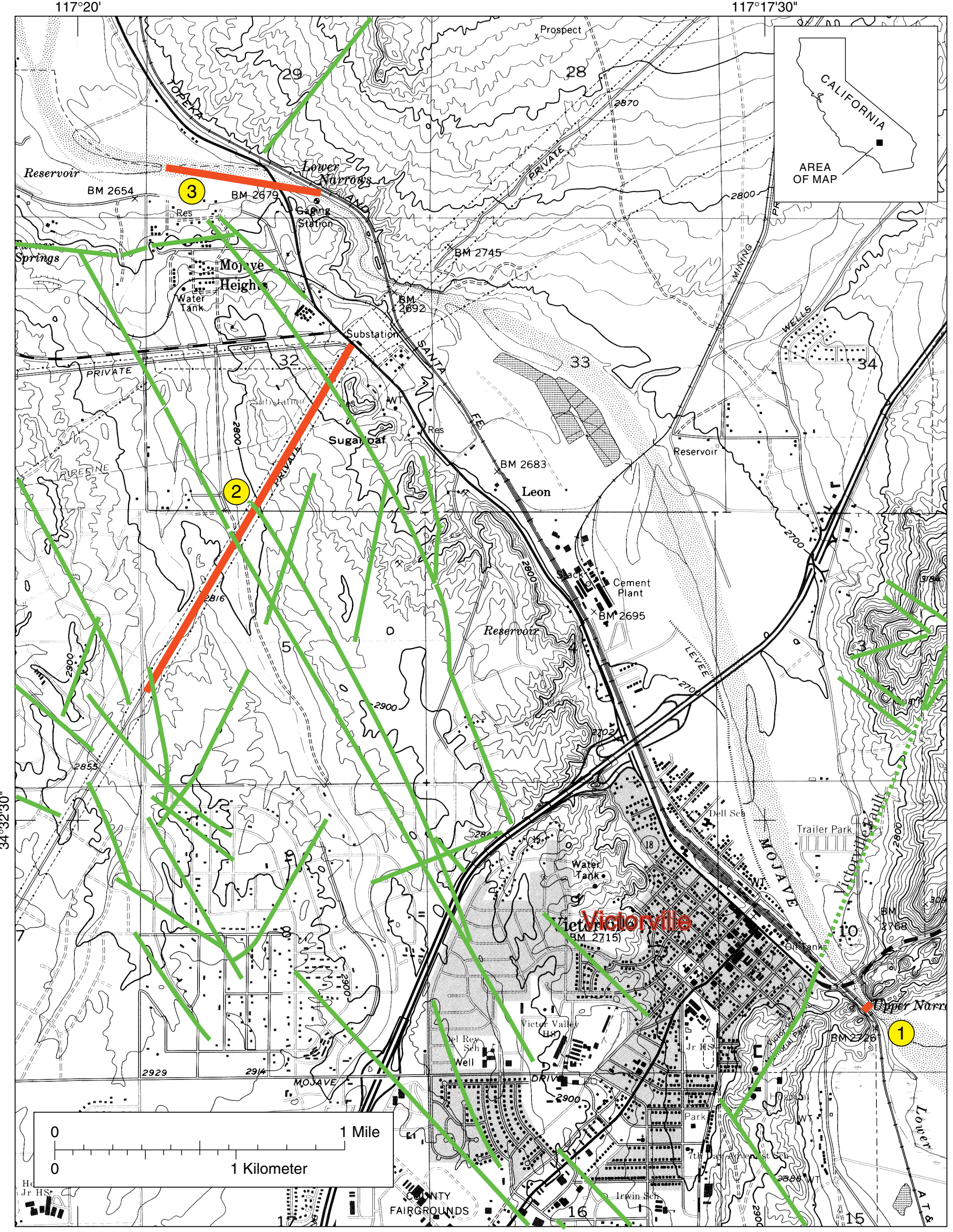

Fig. 29 Map of Victorville showing location of seismic lines (thick red lines) from Catchings et al., (2000). Green lines are geologic lineaments (Cox, unpub. map) including Victorville Fault of Bowen (1954); dotted where concealed. Northwestward projection of these lineaments would place them in the OU-1 area of this study. 


\section{References}

Catchings, R. D., and M. J. Rymer, 1996, Seismic images beneath the northern section of Camp Navajo, Arizona, Report to the Northern Arizona University, U.S. Army Corps of Engineers, and Tetra Tech, Inc., U. S. Geological Survey Report, 65 pp.

Catchings, R. D., B. F. Cox, M. R. Goldman, G. Gandhok, M. J. Rymer, J. Dingler, P. Martin, A. Christensen, and E. Horta, 2000, Subsurface structure and seismic velocities as determined from high-resolution seismic imaging in the Victorville, California area: Implications for water resources and earthquake hazards, US Geological Survey Open-file Report, 00-123, 70 pp.

Catchings, R. D., E. Horta, M. R. Goldman, M. J. Rymer, and T. R. Burdette, Highresolution seismic imaging for environmental and earthquake hazards assessment at the Raychem Site, Menlo Park, California, U. S. Geological Survey Open-File Report 98-146, 37 pp.

Catchings, R. D., G. Gandhok, M. R. Goldman, E. Horta, M. J. Rymer, P. Martin, and A. Christensen, 1999, Subsurface, high-resolution seismic images from Cherry Valley, San Bernardino County, California: Implications for water resources and earthquake hazards, US Geological Survey Open-file Report 99-26, 57 pp.

Chrisley, S.M., 1997, Geology and hydrogeology of the George Air Force Base vicinity, California (M.S. Thesis): San Jose, California, San Jose State University, 111pp.

Cox, B. F. and J.W.Hillhouse, 2000, Pliocene and Pleistocene evolution of the Mojave river, and associated tectonic development of the Transverse ranges and Mojave desert, based on borehole stratigraphy studied near Victorville, California, US Geological Survey Open-File Report 00-147, 62 pp.

Gandhok, G., R. D. Catchings, M. R. Goldman, E. Horta, M. J. Rymer, P. Martin, and A. Christensen, 1999, High-Resolution Seismic Reflection/Refraction Imaging from Interstate 10 to Cherry Valley Boulevard, Cherry Valley, Riverside County, California: Implications for Water Resources and Earthquake Hazards, US Geological Survey Open-file Report 99-320, 52 pp.

Hole, J. A., 1992, Nonlinear high-resolution three-dimensional seismic traveltime tomography, Journal of Geophysical Research, v. 97, p. 6553-6562.

IT Corporation, 1992, Remedial Investigation,Perable Unit 2, Jp-4 spill, George Air Force Base, California, v.1., San Bernardino, California.

Montgomery Watson (geotechnical consultants), 1995, George Air Force Base Installation Restoration Program OU1 Predesign study (draft report, July 1995), Walnut Creek, California. 